\title{
Import Demand Elasticities and Trade Distortions*
}

\author{
Hiau Looi $\mathrm{Kee}^{\dagger}$ \\ Alessandro Nicita ${ }^{\ddagger}$ \\ Marcelo Olarreaga ${ }^{\S}$
}

\begin{abstract}
To study the effects of tariffs on gross domestic product (GDP) one needs import demand elasticities at the tariff line level that are consistent with GDP maximization. These do not exist. We modify Kohli's (1991) GDP function approach to estimate demand elasticities for 4,625 imported goods in 117 countries. Following Anderson and Neary $(1992,1994)$ and Feenstra (1995), we use these estimates to construct theoretically sound trade restrictiveness indices (TRIs) and GDP losses associated with existing tariff structures. Countries are revealed to be 30 percent more restrictive than their simple or import-weighted average tariffs would suggest. Thus, distortion is nontrivial. GDP losses are largest in the United States, China, India, Mexico and Germany.

JEL classification numbers: F1, F10, F13

Keywords: Import demand elasticities, GDP function, trade restrictiveness, deadweight loss
\end{abstract}

${ }^{*}$ We are grateful to James Anderson, Paul Brenton, Hadi Esfahani, Rob Feenstra, Joe Francois, Kishore Gawande, Catherine Mann, William Martin, Jaime de Melo, Christine McDaniel, Peter Neary, Guido Porto, Claudio Sfreddo, Clinton Shiells, David Tarr, Dominique Van Der Mensbrugghe, L. Alan Winters, and participants at seminars at the Center of Global Development, the Econometric Society Meetings at Brown University, the Empirical Trade Analysis Conference at the Woodrow Wilson International Center, PREM week, University of West Virginia, and the World Bank for helpful comments and discussions. The views expressed here are those of the authors and do not necessarily reflect those of the institutions to which they are affiliated.

${ }^{\dagger}$ Development Research Group, The World Bank, Washington, DC 20433, USA; Tel. (202)473-4155; Fax: (202)522-1159; e-mail: hlkee@worldbank.org

${ }^{\ddagger}$ Development Research Group, The World Bank, Washington DC, 20433, USA; Tel. (202)473-4066; Fax: (202)5221159; e-mail: anicita@worldbank.org

${ }^{\S}$ Development Research Group, The World Bank, Washington, DC 20433, USA, and CEPR, London, UK; Tel. (202)458-8021; Fax: (202)522-1159; e-mail: molarreaga@worldbank.org 


\section{Non-Technical Summary}

This paper proposes a methodology that is consistent with GDP maximization in estimating import demand elasticities for more than 4,000 goods in 117 countries. Import demand is a function of prices of all goods and aggregate endowments as in Kohli's (1991) GDP function approach. We found that homogeneous goods have higher elasticites, and point estimates increase as we increase the level of disaggregation at which elasticities are estimated. Import demand is also more elastic in large and rich countries. Using the estimated import demand elasticities, we compute the effect of tariffs on GDP using the theoretically sound trade restrictiveness index (TRI) developed by Anderson and Neary $(1992,1994)$ and Feenstra (1995). TRI values are on average 30 percent higher than simple or import-weigthed average tariffs. GDP losses are largest in the United States, China, India, Mexico and Germany. 


\section{Introduction}

Import demand elasticities are crucial inputs into many ex-ante analyses of trade reform. To evaluate the impact of regional trade agreements on trade flows or customs revenue, one needs to first answer the question of how trade volumes would adjust. To estimate ad-valorem equivalents of quotas or other non-tariff barriers one often needs to transform quantity impacts into their price equivalent, for which import elasticities are necessary. Moreover, trade policy is often determined at much higher levels of disaggregation than existing import demand elasticities. ${ }^{1}$ This mismatch can lead to serious aggregation biases when calculating the impact of trade interventions that have become more of a surgical procedure. Finally, to compare trade restrictiveness and its associated welfare losses across different countries and time, one would need to have a consistent set of trade elasticities, estimated using the same data and methodology that, ideally, would be consistent with trade theory. These do not exist. The closest substitute and the one often used by trade economists is the survey of the empirical literature put together by Stern et al. (1976). More recent attempts to provide disaggregate estimates of import demand elasticities (although not necessarily price elasticities, but Armington or income elasticities) have been country specific and have mainly focused on the United States. These include Shiells, Stern and Deardorff (1986), Shiells, RolandHolst and Reinert (1993), Blonigen and Wilson (1999), Marquez (1999, 2002, 2003), Broda and Weinstein (2003) and Gallaway, McDaniel and Rivera (2003).

The primary objective of this paper is to fill in this gap by estimating import demand elasticities for over 4,625 goods (at the six digit of the Harmonized System (HS)) in 117 countries. We use a methodology that is consistent with trade theory (i.e., imports are a function of prices and factor endowments), and data sources are identical for all countries and goods. We then use these estimates to construct theoretically sound measures of trade restrictiveness for 88 countries, based on Feenstra's (1995) simplification of Anderson and Neary's (1992, 1994, 2003) trade restrictiveness index (TRI). ${ }^{2}$ The TRI is the uniform tariff that would maintain welfare at the current level under the observed tariff structure. Finally, we used the constructed TRI to calculate the overall

\footnotetext{
${ }^{1}$ Trade policy is (almost by definition) often determined at the tariff line level. To our knowledge the only set of estimates of import demand elasticities at the six digit level of the Harmonized System (HS) that exist in the literature are the one provides by Panagariya et al. (2001) for the import demand elasticity faced by Bangladesh exporters of apparel and the elasticities of substitution across exporters to the US by Broda and Weinstein (2003).

${ }^{2}$ For the other 29 countries, we had no tariff schedules available.
} 
deadweight loss associated with the current tariff structure in each of the 88 countries.

The basic theoretical setup is the production based GDP function approach as in Kohli (1991) and Harrigan (1997). This GDP function approach takes into account general equilibrium effects associated with the reallocation of resources due to exogenous changes in prices or endowments, and has close links to trade theory. Imports are considered as inputs of domestic production, for given exogenous world prices, productivity and endowments. In a world where a significant share of growth in world trade is explained by vertical specialization (Yi, 2003), the fact that imports are treated as inputs into the GDP function - rather than as final consumption goods as in most of the previous literature - seems an attractive feature of this approach. ${ }^{3}$

While Kohli (1991) focuses mainly on aggregate import demand and export supply functions and Harrigan (1997) on industry level export supply functions, this paper modifies the GDP function approach to estimate import price elasticities at the tariff line level (HS six digit). When estimating elasticities at the tariff line level, dealing with cross-price effects can become insurmountable. In order to avoid running out of degrees of freedom in the estimation of the structural parameters of the GDP function, we first re-express each $N$-good economy into $N$ sets of two-good economies using properties associated with price indices in translog GDP functions. This transformation allows us to go from a system of $n$ equations with $n$ price related structural parameters to be estimated in each equation to a system of $n$ equations with 2 price related parameters to be estimated. Another practical problem we are facing is that the Harmonized System of trade classification was only introduced in the late 1980s, so even if we solve the $n$-good problem, we may still run out of degrees of freedom if we were to estimate the different parameters using only the time variation in the data. Thus, assuming that the structural parameters of the GDP function are common across countries (up to a constant) as in Harrigan (1997), we take advantage of the panel dimension of the data set by applying within estimators. Finally, as in Kohli (1991), to ensure that second-order conditions of the GDP maximization program are satisfied we impose the necessary curvature conditions which ensure that all estimated import demand elasticities are negative. This requires estimating the parameters of the import share equation using non-linear least squares.

More than 300,000 import demand elasticities have been estimated. The simple average across

\footnotetext{
${ }^{3}$ Kohli (1991) argues that most imported products when sold in the domestic market have some domestic value added embedded, i.e., marketing and transport costs, which justifies the assumption that they are inputs into the GDP function.
} 
all countries and goods is about -1.67 and the median is -1.08 . They are generally estimated with great precision. The median t-statistics (obtained through bootstrapping) is 11.96 (91 percent of the estimates are significant at the 5 percent level). We also found some interesting patterns in our estimated import demand elasticities that are consistent with some simple hypothesis. First, homogenous goods are shown to be more elastic than heterogenous goods. Second, import demand is more elastic when estimated at the tariff line, rather than at the more aggregate industry level. Third, large countries tend to have more elastic import demands, due probability to a larger availability of domestic substitutes. Fourth, more developed countries tend to have less elastic import demands, mainly driven by a higher share of heterogenous goods in developed countries import demand. In sum, the estimated import demand elasticities exhibit significant variation across countries and products that is consistent with some basic hypothesis.

Using the estimated import demand elasticities, we construct the TRI for 88 countries for which tariff schedules are available. Results suggest that both simple and import-weighted average tariffs tend to underestimate the restrictiveness of a country's tariff regime by an average of 30 percent. Thus, GDP losses can be much larger than suggested by average tariffs. In particular, large losses are found in the United States, China, India, Mexico and Germany.

Section 2 provides the theoretical framework to estimate import demand elasticities, whereas section 3 describes the empirical strategy. Section 4 discusses data sources. Section 5 presents the results and explores patterns across goods and countries. Section 6 applies the estimated import demand elasticities to construct TRIs and deadweight losses associated with existing tariff structures. Section 7 concludes.

\section{Theoretical Model - GDP Function Approach}

The theoretical model follows Kohli's (1991) GDP function approach for the estimation of trade elasticities. We also draw on Harrigan's (1997) treatment of productivity terms in GDP functions. We will first derive the GDP and import demand functions for one country. However, assuming that the GDP function is common across all countries up to a country specific term -which controls for country productivity differences- it is then easily generalized to a multi-country setting in the next section. 
Consider a small open economy in period $t .^{4}$ Let $\mathbf{S}^{t} \subset \mathbf{R}^{N+M}$ be the strictly convex production set in $t$ of its net output vector $q^{t}=\left(q_{1}^{t}, q_{2}^{t}, \ldots, q_{N}^{t}\right)$ and factor endowment vector $v^{t}=$ $\left(v_{1}^{t}, v_{2}^{t}, \ldots, v_{M}^{t}\right) \geq 0$. For the elements in the net output vector $q^{t}$, we adopt the convention that positive numbers denote outputs, which include exports, and negative numbers denote inputs, which include imported goods. We consider imported goods and competing domestically produced goods as differentiated products. Similarly domestic products sold in the domestic market are differentiated from products sold in foreign markets (i.e., exported).

Given the exogenous world price vector $\tilde{p}^{t}=\left(\tilde{p}_{1}^{t}, \tilde{p}_{2}^{t}, \ldots, \tilde{p}_{N}^{t}\right)>0$, the country specific endowments, $v^{t}$, and $N$-dimensional diagonal Hicks-neutral productivity matrix $\mathbf{A}^{t}=\operatorname{diag}\left\{A_{1}^{t}, A_{2}^{t}, \ldots, A_{N}^{t}\right\}$, perfect competition leads firms to choose a mixed of goods that maximizes GDP in each period $t$ :

$$
\begin{aligned}
G^{t}\left(\tilde{p}^{t}, \mathbf{A}^{t}, v^{t}\right) & \equiv \max _{q^{t}}\left\{\tilde{p}^{t} \cdot \mathbf{A}^{t} q^{t}:\left(q^{t}, v^{t}\right) \in \mathbf{S}^{t}\right\} \Rightarrow \\
G^{t}\left(\tilde{p}^{t} \mathbf{A}^{t}, v^{t}\right) & \equiv \max _{q^{t}}\left\{\tilde{p}^{t} \mathbf{A}^{t} \cdot q^{t}:\left(q^{t}, v^{t}\right) \in \mathbf{S}^{t}\right\}
\end{aligned}
$$

where $G^{t}\left(\tilde{p}^{t} \mathbf{A}^{t}, v^{t}\right)$, is the maximum value of goods the economy can produce given prices, Hicksneutral productivity and factor endowments in period $t$. It equals to the total value of output for exports and final domestic consumption minus the total value of imports ( $q_{n}^{t}<0$ for imports). In other words, the optimal net output vector is chosen to maximize GDP in equilibrium, given prices, productivity and endowments. We shall refer to the optimal net output vector as the GDP maximizing net output vector, which includes GDP maximizing import demands.

As shown in Harrigan (1997), Equation (2) highlights that price and productivity enter multiplicatively in the GDP function, $G^{t}\left(\tilde{p}^{t} \mathbf{A}^{t}, v^{t}\right)$. This property allows us to re-express the GDP function, by defining the productivity inclusive price vector, $p^{t}=\left(p_{1}^{t}, p_{2}^{t}, \ldots, p_{N}^{t}\right)>0$ :

$$
\begin{aligned}
G^{t}\left(p^{t}, v^{t}\right) & =\max _{q^{t}}\left\{p^{t} \cdot q^{t}:\left(q^{t}, v^{t}\right) \in \mathbf{S}^{t}\right\}, \text { with } \\
p^{t} & \equiv \tilde{p}^{t} \mathbf{A}^{t}, \text { and } p_{n}^{t} \equiv \tilde{p}_{n}^{t} A_{n}^{t}, \forall n
\end{aligned}
$$

Notice that the productivity inclusive price vector, $p^{t}$, is no longer common across country even though the world price vector, $\tilde{p}^{t}$, is identical across countries. This allows the model to better fit

\footnotetext{
${ }^{4}$ For a discussion of the relevance of the small country assumption when estimating trade elasticities, see Riedel (1988), Athukorala and Riedel (1994) and Panagariya et al. (2001).
} 
the data where different world prices are observed for the same good in different countries. In a recent study, Schott (2004) successfully explains variation in unit values for goods in the same tariff line but in different countries with GDP per capita levels. To the extent that GDP per capita is a proxy for labor productivity, Schott's finding provides support for our productivity inclusive price level, $p^{t}$.

For $G^{t}\left(p^{t}, v^{t}\right)$ to be a well defined GDP function, it is assumed to be homogeneous of degree one with respect to prices. Moreover, strict convexity of $\mathbf{S}^{t}$ also ensures that the second order sufficient conditions are satisfied, such that $G^{t}\left(p^{t}, v^{t}\right)$ is twice differentiable and it is convex in $p^{t}$ and concave in $v^{t}$. To derive import demand function, we apply the Envelope Theorem, which shows that the gradient of $G^{t}\left(p^{t}, v^{t}\right)$ with respect to $p^{t}$ is the GDP maximizing net output vector, $q^{t}\left(p^{t}, v^{t}\right)$ :

$$
\frac{\partial G^{t}\left(p^{t}, v^{t}\right)}{\partial p_{n}^{t}}=q_{n}^{t}\left(p^{t}, v^{t}\right), \forall n=1, \ldots, N
$$

Thus if good $n$ is an imported good, Equation (5) would be the GDP maximizing import demand function of good $n$, which is a function of prices and endowments. It also implies that an increase in import prices would reduce GDP (i.e., $q_{n}^{t}<0$ if $n$ is an imported good). Given that $G^{t}\left(p^{t}, v^{t}\right)$ is continuous and twice differentiable, and is convex and homogeneous of degree one with respect to prices, the Euler Theorem implies that $q_{n}^{t}$ is homogenous of degree zero in prices, has non-negative own price effects and has symmetric cross price effects: ${ }^{5}$

$$
\frac{\partial^{2} G^{t}\left(p^{t}, v^{t}\right)}{\partial p_{n}^{t} \partial p_{k}^{t}}=\left\{\begin{array}{l}
\frac{\partial q_{n}^{t}\left(p^{t}, v^{t}\right)}{\partial p_{n}^{t}} \geq 0, \forall n=k \\
\frac{\partial q_{n}^{t}\left(p^{t}, v^{t}\right)}{\partial p_{k}^{t}}=\frac{\partial q_{k}^{t}\left(p^{t}, v^{t}\right)}{\partial p_{n}^{t}}, \forall n \neq k
\end{array}\right.
$$

In other words, for every final good, including exports, a price increase raises output supply; for every input, including imports, an increase in prices decreases input demand. In addition, if an increase in the price of an imported input causes supply of an exported output to decrease, then an increase in the price of the exported output would increase the demand of the imported input in the same magnitude.

Equation (5) shows that the GDP maximizing import demand function of good $n$ is a function

\footnotetext{
${ }^{5}$ The latter by Young's Theorem.
} 
of prices and factor endowments. Thus, the implied own price effects of imports, and the import demand elasticities, are therefore conditioned on prices of other goods and aggregate endowments being fixed. Thus, the GDP maximizing import demand functions do not depend on income or utility, unlike the expenditure minimizing Hicksian import demand functions or the utility maximizing Marshallian import demand functions. This is because, aggregate factor income and welfare are in fact endogenous to prices and endowments. Such a set up is more relevant for general equilibrium trade models, but may not be relevant for partial equilibrium micro models which often take aggregate income as exogenous. As a result, comparing the GDP maximizing import demand elasticities to the existing Hicksian or Marshallian import demand elasticities in the literature may not be appropriate. Finally, we will not be able to derive income elasticities from the GDP maximizing import demand functions, but instead, we would be able to estimate the Rybczynski elasticities from Equation (5), which shows how import demand reacts to changes in factor endowments. ${ }^{6}$

To implement the above GDP function empirically, let's assume, without loss of generality, that $G^{t}\left(p^{t}, v^{t}\right)$ follows a flexible translog functional form with respect to prices and endowments, where $n$ and $k$ index goods, and $m$ and $l$ index factor endowments:

$$
\begin{aligned}
\ln G^{t}\left(p^{t}, v^{t}\right)= & a_{00}^{t}+\sum_{n=1}^{N} a_{0 n}^{t} \ln p_{n}^{t}+\frac{1}{2} \sum_{n=1}^{N} \sum_{k=1}^{N} a_{n k}^{t} \ln p_{n}^{t} \ln p_{k}^{t} \\
& +\sum_{m=1}^{M} b_{0 m}^{t} \ln v_{m}^{t}+\frac{1}{2} \sum_{m=1}^{M} \sum_{l=1}^{M} b_{m l}^{t} \ln v_{m}^{t} \ln v_{l}^{t} \\
& +\sum_{n=1}^{N} \sum_{m=1}^{M} c_{n m}^{t} \ln p_{n}^{t} \ln v_{m}^{t}
\end{aligned}
$$

where all the translog parameters $a, b$ and $c^{\prime} s$ are indexed by $t$ to allow for changes over time. In order to make sure that Equation (7) satisfies the homogeneity and symmetry properties of a GDP function, we impose the following restrictions:

$$
\sum_{n=1}^{N} a_{0 n}^{t}=1, \sum_{k=1}^{N} a_{n k}^{t}=\sum_{n=1}^{N} c_{n m}^{t}=0, a_{n k}^{t}=a_{k n}^{t}, \forall n, k=1, \ldots, N, \forall m=1, \ldots, M
$$

Furthermore, if we assume that the GDP function is homogeneous of degree one in factor endow-

\footnotetext{
${ }^{6}$ See Section 5.3 of Kohli (1991) for a thorough discussion on the various import demand specifications.
} 
ments, then we also need to impose the following restrictions:

$$
\sum_{n=1}^{N} b_{0 n}^{t}=1, \sum_{k=1}^{N} b_{n k}^{t}=\sum_{m=1}^{M} c_{n m}^{t}=0, b_{n k}^{t}=b_{k n}^{t}, \forall n, k=1, \ldots, N, \forall m=1, \ldots, M
$$

Given the translog functional form and the symmetry and homogeneity restrictions, the derivative of $\ln G^{t}\left(p^{t}, v^{t}\right)$ with respect to $\ln p_{n}^{t}$ gives us the equilibrium share of good $n$ in GDP at period $t:$

$$
\begin{aligned}
s_{n}^{t}\left(p^{t}, v^{t}\right) & \equiv \frac{p_{n}^{t} q_{n}^{t}\left(p^{t}, v^{t}\right)}{G^{t}\left(p^{t}, v^{t}\right)}=a_{0 n}^{t}+\sum_{k=1}^{N} a_{n k}^{t} \ln p_{k}^{t}+\sum_{m=1}^{M} c_{n m}^{t} \ln v_{m}^{t} \\
& =a_{0 n}^{t}+a_{n n}^{t} \ln p_{n}^{t}+\sum_{k \neq n} a_{n k}^{t} \ln p_{k}^{t}+\sum_{m=1}^{M} c_{n m}^{t} \ln v_{m}^{t}, \forall n=1, \ldots, N,
\end{aligned}
$$

where $s_{n}^{t}$ is the share of imports of good $n$ in GDP $\left(s_{n}^{t}<0\right.$ if good $n$ is an input as in the case of imports). From Equation (10) it can be shown that, if good $n$ is an imported good, then the import demand elasticity of good $n$ derived from its GDP maximizing demand function is: ${ }^{7}$

$$
\varepsilon_{n n}^{t} \equiv \frac{\partial q_{n}^{t}\left(p^{t}, v^{t}\right)}{\partial p_{n}^{t}} \frac{p_{n}^{t}}{q_{n}^{t}}=\frac{a_{n n}^{t}}{s_{n}^{t}}+s_{n}^{t}-1 \leq 0, \forall s_{n}^{t}<0
$$

Thus we can infer the import demand elasticities once $a_{n n}$ is properly estimated based on Equation (10). Note that the size of the import elasticity, $\varepsilon_{n n}^{t}$, depends on the sign of $a_{n n}^{t}$, which captures the changes in the share of good $n$ in GDP when price of good $n$ increases by 1 percent:

$$
\varepsilon_{n n}^{t}\left\{\begin{array}{l}
<-1 \text { if } a_{n n}^{t}>0 \\
=-1 \text { if } a_{n n}^{t}=0 \\
>-1 \text { if } a_{n n}^{t}<0
\end{array}\right.
$$

The rationale is straightforward. If the share of imports in GDP does not vary with import prices $\left(a_{n n}^{t}=0\right)$, then the implied import demand is unitary elastic such that an increase in import price induces an equi-proportional decrease in import quantities and leaves the value of imports unchanged. If the share of imports in GDP, which is negative by construction, decreases with

\footnotetext{
${ }^{7}$ Cross-price elasticities of import demand are given by: $\varepsilon_{n k}^{t} \equiv \frac{\partial q_{n}^{t}\left(p^{t}, v^{t}\right)}{\partial p_{k}^{t}} \frac{p_{k}^{t}}{q_{n}^{t}}=\frac{a_{n k}^{t}}{s_{n}^{t}}+s_{k}^{t}, \forall n \neq k$.
} 
import price $\left(a_{n n}^{t}<0\right)$, then the implied import demand is inelastic, so that an increase in import price induces a less than proportionate decrease in import quantities. Finally, if the share of import in GDP increases with import prices $\left(a_{n n}^{t}>0\right)$, then the implied import demand must be elastic such that an increase in the price of import induces a more than proportionate decrease in import quantity. $^{8}$

\section{Empirical Strategy}

With data on output shares, unit values and factor endowments, Equation (10) is the basis of our estimation of import elasticities. In principle, we could first estimate the own price effects, $a_{n n}^{t}$, for every good according to Equation (10), and apply Equation (11) to derive the implied estimated elasticities, since the own price elasticity is a linear function of own partial effects. There are, however, at least three problems with the estimation of the elasticities using (10). First, there are literally thousands of goods traded among the countries in any given year. Moreover, there is also a large number of non-traded commodities that compete for scarce factor endowments and contribute to GDP in each country. Thus the number of explanatory variables in Equation (10) could easily exhausts our degrees of freedom or introduce serious collinearity problems. Second, even after solving this first problem, we could also run out of degrees of freedom given the short time span of trade data available at the six digit of the HS - which only started being used in the late 1980s. Finally, there is nothing so far to ensure that the estimated elasticities satisfy second order conditions of GDP maximization, i.e., there are negative. We tackle these three problems in turn.

\subsection{From an $N$ good economy to $N$ sets of two-good economies}

Given that our objective is to estimate the own price effect, $a_{n n}^{t}$, for every good $n$, we re-express the $N$-good GDP function into $N$ "two-good economies" producing goods $n$ and $-n$ :

$$
G^{t}\left(p_{n}^{t}, p_{-n}^{t}, v^{t}\right) \equiv \max _{q^{t}}\left\{p_{n}^{t} q_{n}^{t}+p_{-n}^{t} q_{-n}^{t}:\left(q^{t}, v^{t}\right) \in \mathbf{S}^{t}\right\}
$$

\footnotetext{
${ }^{8}$ Kohli (1991) found an inelastic demand for the aggregate US imports with $a_{n n}<0$, while highly elastic demand for the durables and services imports of the US, with the corresponding $a_{n n}>0$, when the aggregate import is broken down into 3 disaggregate groups.
} 
where for every good $n$, we construct a price index, $p_{-n}^{t}$, and a quantity index, $q_{-n}^{t}$, such that their product equals the sum of the value of all other goods in GDP,

$$
p_{-n}^{t} q_{-n}^{t}=\sum_{k \neq n, k=1}^{N} p_{k}^{t} q_{k}^{t}
$$

With the appropriate price and quantity indexes of good $-n$, the translog specification of Equation (12) and the implied share equations for good $n$ could then be use to estimate the own price effect of every good $n$ in this two good economy:

$$
\begin{aligned}
\ln G^{t}\left(p_{n}^{t}, p_{-n}^{t}, v^{t}\right)= & a_{00}^{t}+a_{0 n}^{t} \ln p_{n}^{t}+a_{0-n}^{t} \ln p_{-n}^{t} \\
& +\frac{1}{2} a_{n n}^{t}\left(\ln p_{n}^{t}\right)^{2}+\frac{1}{2} a_{-n-n}^{t}\left(\ln p_{-n}^{t}\right)^{2}+a_{n-n}^{t} \ln p_{n}^{t} \ln p_{-n}^{t} \\
& +\sum_{m=1}^{M} b_{0 m}^{t} \ln v_{m}^{t}+\frac{1}{2} \sum_{m=1}^{M} \sum_{l=1}^{M} b_{m l}^{t} \ln v_{m}^{t} \ln v_{l}^{t} \\
& +\sum_{m=1}^{M} c_{n m}^{t} \ln p_{n}^{t} \ln v_{m}^{t}+\sum_{m=1}^{M} c_{-n m}^{t} \ln p_{-n}^{t} \ln v_{m}^{t}, \\
s_{n}^{t}\left(p_{n}^{t}, p_{-n}^{t}, v^{t}\right)= & a_{0 n}^{t}+a_{n n}^{t} \ln p_{n}^{t}+a_{n-n}^{t} \ln p_{-n}^{t}+\sum_{m=1}^{M} c_{n m}^{t} \ln v_{m}^{t}, \forall n .
\end{aligned}
$$

For the above two good economy to be equivalent to the $N$ good economy, it is necessary for Equations (13) and (14) to be equivalent to Equations (7) and (10). This could be true if $\ln p_{-n}$ is constructed in the following way. ${ }^{9}$ According to Caves, Christensen and Diewert (1982), if $G^{t}\left(p^{t}, v^{t}\right)$ follows a translog functional form and assuming that all the translog parameters are time invariant, $a_{n k}^{t}=a_{n k}, \forall n, k, t$, then a Tornqvist price index is the exact price index of $G^{t}\left(p^{t}, v^{t}\right)$ :

$$
P_{T}\left(p^{t}, p^{t-1}, v^{t}, v^{t-1}\right) \equiv \prod_{n=1}^{N}\left(\frac{p_{n}^{t}}{p_{n}^{t-1}}\right)^{\frac{1}{2}\left(s_{n}^{t}+s_{n}^{t-1}\right)}
$$

and is equal to the geometric mean of the theoretical GDP price index $P^{t}\left(p^{t}, p^{t-1}, v^{t-1}\right) \equiv$ $\frac{G^{t-1}\left(p^{t}, v^{t-1}\right)}{G^{t-1}\left(p^{t-1}, v^{t-1}\right)}$ and $P^{t}\left(p^{t}, p^{t-1}, v^{t}\right) \equiv \frac{G^{t}\left(p^{t}, v^{t}\right)}{G^{t}\left(p^{t-1}, v^{t}\right)}$. Re-writing Equation (15) by separating price index of good $n$ from the product term, and taking logarithm on both sides of the equations, we obtain

\footnotetext{
${ }^{9}$ For a more detailed description see Appendix A.
} 
the price of good $-n$ :

$$
\begin{aligned}
\ln P_{T}\left(p^{t}, p^{t-1}, v^{t}, v^{t-1}\right) & =\frac{1}{2}\left(s_{n}^{t}+s_{n}^{t-1}\right) \ln \frac{p_{n}^{t}}{p_{n}^{t-1}}+\sum_{k \neq n, k=1}^{N} \frac{1}{2}\left(s_{k}^{t}+s_{k}^{t-1}\right) \ln \frac{p_{k}^{t}}{p_{k}^{t-1}} \\
& =\frac{1}{2}\left(s_{n}^{t}+s_{n}^{t-1}\right) \ln \frac{p_{n}^{t}}{p_{n}^{t-1}}+\frac{1}{2}\left(s_{-n}^{t}+s_{-n}^{t-1}\right) \ln \frac{p_{-n}^{t}}{p_{-n}^{t-1}} \text { with } \\
\ln \frac{p_{-n}^{t}}{p_{-n}^{t-1}} & \equiv \frac{1}{\frac{1}{2}\left(s_{-n}^{t}+s_{-n}^{t-1}\right)} \sum_{k \neq n, k=1}^{N} \frac{1}{2}\left(s_{k}^{t}+s_{k}^{t-1}\right) \ln \frac{p_{k}^{t}}{p_{k}^{t-1}} .
\end{aligned}
$$

Thus, in a two-good economy, the overall GDP deflator is the weighted average between the price changes of good $n$ and the composite good $-n$. In addition, according to Equation (17), with information on the overall GDP deflator and the unit value of good $n$, the change in the price index of the composite good $-n$ is the difference between the change in the overall GDP deflator at period $t$ and the weighted change in the price of good $n$ :

$$
\ln p_{-n}^{t}=\ln p_{-n}^{t-1}+\frac{1}{\frac{1}{2}\left(s_{-n}^{t}+s_{-n}^{t-1}\right)}\left(\ln P_{T}\left(p^{t}, p^{t-1}, v^{t}, v^{t-1}\right)-\frac{1}{2}\left(s_{n}^{t}+s_{n}^{t-1}\right) \ln \frac{p_{n}^{t}}{p_{n}^{t-1}}\right) .
$$

By normalizing prices of all goods, both $n$ and $-n$, to 1 in the first year of our sample, we can then construct price indexes for goods $n$ and $-n$ in each sample country.

Imposing the additional assumption that all parameters in the GDP functions are time invariant, and substituting Equation (17) into Equation (14) and equating Equation (14) with Equation (10), it is clear that the following is necessarily true for the two good economy to be equivalent to the $N$ good economy for every $k \neq n$ :

$$
a_{n-n} \frac{\frac{1}{2}\left(s_{k}^{t}+s_{k}^{t-1}\right)}{\frac{1}{2}\left(s_{-n}^{t}+s_{-n}^{t-1}\right)} \equiv a_{n k}, \forall n, \text { and } k \neq n
$$

In order words, with the proper construction of $\ln p_{-n}^{t}$ according to Equation (18) for every good $n$, we can reduce a $N$-good economy which has $N$ share equations with $N$ price parameters each into $N$ two good economies, with $N$ share equations with 2 price parameters each. The parameters between the $N$-good economy and the two-good economy are related as indicated by Equation (19). A more detailed proof is provided in the Appendix.

Thus, with the properly constructed $\ln p_{-n}^{t}$ and the two good share equation, we reduce the 
challenging problem of estimating $n-1$ cross price effects for each good $n$ into simply estimating one own price effect, $a_{n n}$, and a cross price effect $a_{n-n}$. We further impose homogeneity constraints to the two good share equation, so that $a_{n n}+a_{n-n}=0$ and $\sum_{m=1}^{M} c_{n m}^{t}=0$, and express the two good share equation in terms of price of good $n$ relative to good $-n$ and factor endowment $m$ relative to land, $l$ :

$$
s_{n}^{t}\left(p_{n}^{t}, p_{-n}^{t}, v^{t}\right)=a_{0 n}+a_{n n} \ln \frac{p_{n}^{t}}{p_{-n}^{t}}+\sum_{m \neq l, m=1}^{M} c_{n m} \ln \frac{v_{m}^{t}}{v_{l}^{t}}+\mu_{n}^{t}, \forall n .
$$

With an additive stochastic error term, $\mu_{n}^{t}$, to capture measurement errors, Equation (20) is the basis used for the estimation of own price effect, $a_{n n}$, and hence own price import elasticity, $\varepsilon_{n n} \cdot{ }^{10}$

\subsection{Using the panel variation in the data}

Due to the limited time variation in the data and to take advantage of the panel nature of the sample, Equation (20) is pooled across countries and years for each good $n$. We assume that the structural parameters of the GDP function are time and country invariant (up to a constant) as in Harrigan (1997). Notice that even though we assume that $a_{n n}$ is common across all countries, the implied own price elasticities will still vary across countries, given that $s_{n c}^{t}$ is country specific (see Equation (11)).

Pooling the data across countries and years and introducing country subscript $c$ in Equation (20), we further assume that the stochastic term, $\mu_{n}^{t}$, has a two way error: one is country specific, $a_{n c}$, and the other one is year specific, $a_{n}^{t}$ :

$$
\begin{aligned}
s_{n c}^{t}\left(p_{n c}^{t}, p_{-n c}^{t}, v_{c}^{t}\right) & =a_{0 n}+a_{n n} \ln \frac{p_{n c}^{t}}{p_{-n c}^{t}}+\sum_{m \neq l, m=1}^{M} c_{n m} \ln \frac{v_{m c}^{t}}{v_{l c}^{t}}+\mu_{n c}^{t}, \forall n, c, \text { with } \\
\mu_{n c}^{t} & =a_{n c}+a_{n}^{t}+u_{n c}^{t}, u_{n c}^{t} \sim \mathcal{N}\left(0, \sigma_{n}\right), \Rightarrow \\
s_{n c}^{t}\left(p_{n c}^{t}, p_{-n c}^{t}, v_{c}^{t}\right) & =a_{0 n}+a_{n c}+a_{n}^{t}+a_{n n} \ln \frac{p_{n c}^{t}}{p_{-n c}^{t}}+\sum_{m \neq l, m=1}^{M} c_{n m} \ln \frac{v_{m c}^{t}}{v_{l c}^{t}}+u_{n c}^{t}, \forall n .
\end{aligned}
$$

Equation (21) allows for country and year fixed-effects, which enable us to capture any system-

\footnotetext{
${ }^{10}$ Note that in this two good economy set up, there is a system of two equations for each good, one for $n$ and one for $-n$. To avoid singularity in the estimation, we drop the equation for $-n$ such that no cross equation restrictions are necessary, and the estimation procedure is reduced to a single equation estimation.
} 
atic shift in the share equation that is country or year specific. We apply the within estimator to estimate Equation (21), by appropriately removing the country means and year means from each variable (and adding back the overall mean), and express all variables in deviation form (with suffix d) :

$$
d s_{n c}^{t}=a_{0 n}+a_{n n} d \ln \frac{p_{n c}^{t}}{p_{-n c}^{t}}+\sum_{m \neq l, m=1}^{M} c_{n m} d \ln \frac{v_{m c}^{t}}{v_{l c}^{t}}+u_{n c}^{t}, \forall n
$$

\subsection{Ensuring second order conditions}

For Equation (22) to be the solution to the GDP maximization program, second order necessary conditions need to be satisfied (the Hessian matrix needs to be negative semi-definite). Such conditions are also known as the curvature conditions which ensure that the GDP function is smooth, differentiable, and convex with respect to output prices and concave with respect to input

prices and endowments. This implies that the estimated import elasticities are not positive (see Equation (6)), i.e.:

$$
a_{n n} \geq s_{n c}^{t}\left(1-s_{n c}^{t}\right), \forall c, t, n
$$

Given that by construction $s_{n c}^{t}<0$, the above is true if

$$
a_{n n} \geq \bar{s}_{n}\left(1-\bar{s}_{n}\right)
$$

where $\bar{s}_{n}$ is the maximum (negative) share in the sample for good $n$. For all variables we denote such an observation (the $\bar{s}_{n}$ maximum) with an over-bar. To ensure that the curvature conditions are satisfied, we first need to difference all observations with respect to the observation where the curvature condition is most likely to be violated, and add back $\bar{s}_{n}$, so that the expected value of the intercept equals the maximum share:

$$
\begin{aligned}
d s_{n c}^{t}-d \bar{s}_{n}+\bar{s}_{n}= & \tilde{a}_{0 n}+a_{n n}\left(d \ln \frac{p_{n c}^{t}}{p_{-n c}^{t}}-d \ln \frac{\bar{p}_{n}}{\bar{p}_{-n}}\right) \\
& +\sum_{m \neq l, m=1}^{M} c_{n m}\left(d \ln \frac{v_{m c}^{t}}{v_{l c}^{t}}-d \ln \frac{\bar{v}_{m}}{\bar{v}_{l}}\right)+u_{n c}^{t}-\bar{u}, \forall n .
\end{aligned}
$$

Such a procedure ensure that the expected value of the intercept is equal to the maximum share, $\bar{s}_{n}$, without affecting the slope coefficients, $a_{n n}$ and $c_{n m}$. We then impose the constraint provided 
by Equation (23), by reparameterizing $a_{n n}$ in Equation (24) as follows:

$$
a_{n n}=\tau_{n n}^{2}+\tilde{a}_{0 n}\left(1-\tilde{a}_{0 n}\right)
$$

where $\tilde{a}_{0 n}$ and $\tau_{n} n$ are parameters to be estimated nonlinearly. Thus, the final version of the share equation is

$$
\begin{aligned}
d s_{n c}^{t}-d \bar{s}_{n}+\bar{s}_{n}= & \tilde{a}_{0 n}+\left(\tau_{n n}^{2}+\tilde{a}_{0 n}-\tilde{a}_{0 n}^{2}\right)\left(d \ln \frac{p_{n c}^{t}}{p_{-n c}^{t}}-d \ln \frac{\bar{p}_{n}}{\bar{p}_{-n}}\right) \\
& +\sum_{m=1}^{M} c_{n m}\left(d \ln \frac{v_{m c}^{t}}{v_{l c}^{t}}-d \ln \frac{\bar{v}_{m}}{\bar{v}_{l}}\right)+\tilde{u}_{n c}^{t}
\end{aligned}
$$

where regression error term, $\tilde{u}_{n c}^{t}$, has a normal distribution with expected value of zero and variance $\tilde{\sigma}^{2}$. Given that $\tilde{a}_{0 n}$ and $\tau$ is nonlinear with respect to $\tilde{u}_{n c}^{t}$, nonlinear estimation techniques are necessary.

Note that this may not be enough to ensure that all import demand elasticities are negative. Indeed, if the estimated $\tilde{a}_{0 n}$ turns out to be smaller than $\bar{s}_{n}$, then some of the elasticities may still turn out to be non-negative. In other words, this is not a deterministic setup and $\bar{s}_{n}$ is only the $E\left(\tilde{a}_{0 n}\right)$. Thus, when estimating the import share equation prior to differencing with respect to the observation where the second order condition is more likely to be violated, if the error term of a particular observation is positive, then the estimated elasticity for this observation will also be positive. In those cases we impose $\tilde{a}_{0 n} \equiv \bar{s}_{n}$ in the estimation procedure, which ensures that all elasticities are negative. This occurs in less than 3 percent of the sample.

Finally, given that the import demand elasticity is non-linear in the estimated parameters we estimate the standard errors of the import demand elasticities through bootstrapping (50 random draws for each six digit HS good).

\section{Data}

The data consist of import values and quantities reported by different countries to the UN Comtrade system at the six digit of the HS (around 4,600 products). ${ }^{11}$ The HS was introduced in 1988, but

\footnotetext{
${ }^{11}$ It is available at the World Bank through the World Integrated Trade System (WITS).
} 
a wide use of this classification system only started in the mid 1990s. The basic data set consists of an unbalanced panel of imports for 117 countries at the six digit level of the HS for the period 1988-2002. The number of countries obviously varies across products depending on the presence of import flows and on the availability of trade statistics at the HS level.

There are three factor endowments included in the regression: labor, capital stock and agriculture land. Data on labor force and agriculture land are from the World Development Indicators (WDI, 2003). Data on capital endowments are constructed using the perpetual inventory method based on real investment data in WDI (2003).

The estimation sample did not include tariff lines where the recorded trade value at the at the six digit level of the HS was below $\$ 50,000$ per year. This eliminated less than 0.1 percent of imports in the sample, and it is necessary in order to avoid biasing our results with economically meaningless imports. The elasticities are constructed following Equation (11), where the import share is the sample average (i.e., we constrained the elasticities to be time invariant). We also purged the reported results from extreme values by dropping from the sample the top and bottom 0.5 percent of the estimates.

\section{Empirical Results}

To be precise, we estimate a total of 315,451 import demand elasticities at the six digit level of the HS for 117 countries. The simple average across all countries and goods is -1.67 and the standard deviation is 2.47 suggesting quite a bit of variance in the estimates. Figure 1 shows the Kernel density estimate of the distribution of all estimated elasticities. The vertical line to the left denotes the sample mean $(-1.67)$, and the line to the right the sample median $(-1.08)$.

All import demand elasticities are quite precisely estimated. The median t-statistics is around -11.96. Around 89 percent of the elasticities are significant at the 1 percent level; 91 percent at the 5 percent level and 93 percent at the 10 percent level.

The estimates vary substantially across countries. The top three countries with the highest average elasticity are Japan, United States and Brazil (-4.05, -3.39 and -3.38, respectively). The three countries with the lowest average import demand elasticities are Surinam, Belize and Guyana $(-1.02,-1.03$ and -1.03 , respectively). Table 1 summarizes the elasticities by country providing the 
simple average, the standard deviation, the median and the import-weighted average elasticity.

The estimate also show some variation across products. Goods with the more elastic import demands (on average across countries) at the six digit level of the HS include HS 520635 (Cotton yarn), 854290 (Electronic integrated circuits), and 100810 (Buckwheat), with average elasticities of $-16.29,-12.89$ and -11.72 , respectively. Similarly, the least elastic import demands are found in HS 140291 (Vegetable residuals for stuffing), HS 420232 (Articles for pocket, plastic/textile materials) and HS 290521 (Allyl Alcohol), with average elasticities of -0.52, -0.65 and -0.66.

Given the lack of existing estimates at the tariff line level, we need some guidelines to judge our results. Below we enumerate some predictions we expect to find in the estimated import demand elasticities:

1. The import demand for homogenous goods is more elastic than for heterogenous goods. Rauch (1999) classifies goods into these categories, which we can use to test the hypothesis.

2. Import demand is more elastic at the disaggregate level - the substitution effect between cotton shirts and wool shirts is larger than the substitution effect between shirts and pants, or garment and electronics. Thus, we expect the HS six digit estimates to be larger in magnitude (more negative) than estimates at a more aggregate level, i.e., three digit level ISIC classification, which is formed of 29 industries, respectively. Broda and Weinstein (2004) uses a similar guideline for their elasticities of substitution estimates.

3. Import demand is more elastic in large countries. The rationale is that in large countries there is a larger range of domestically produced goods and therefore the sensitivity of import demand to import prices is expected to be larger. In other words, it is easier to substitute away from imports into domestically produced goods in large economies.

4. Import demand is less elastic in more developed countries. The relative demand for heterogenous goods is probably higher in rich countries. Given that heterogenous goods are less elastic, we expect the import demand to be less elastic in rich countries.

As a preview of the first prior that homogenous goods are more elastic, we compare the estimated import demand elasticities for Metal (HS 72-83) with those of Machinery (HS 84-89), where the former are expected to be more homogenous. The average import demand elasticity of Metal is 
-1.62 while it is -1.39 for Machinery. A simple mean test supported the hypothesis that Metal import demand is more elastic than that of the Machinery, with a t-statistics of -13.02 . Figure 2 presents the two Kernel density distribution of the estimated import demand elasticities for Metal and Machineries tariff lines across all countries.

To properly test the homogenous vs heterogenous goods hypotheses, we use Rauch's (1999) classification. Rauch groups four digit SITC goods into three categories: differentiated, reference priced and homogenous goods. By matching our HS six digit products to the SITC schedule, we are able to classify our products according to Rauch's schedule. Table 2 provides the sample averages, medians and standard deviations of the estimated import demand elasticities according to the three categories of goods. It is clear that the average elasticity is larger in magnitude for homogenous goods, follows by the reference priced and differentiated goods. Simple mean tests supported the hypotheses that homogenous goods are more elastic than reference priced goods, and reference priced goods are more elastic than differentiated goods. The t-statistics of the two tests are 7.23 and 19.50 respectively. Similarly, the median elasticity for differentiated goods is smaller in magnitude than both reference priced and homogeneous goods. A simple rank test shows that the median elasticity of differentiated goods is statistically smaller in magnitude than the rest, with a p-value close to 0 , while the difference between the median elasticities of reference price goods and homogenous goods is not statistically significant. All this suggests that differentiated goods are less elastic than reference priced and homogeneous goods, which confirms our first a priori.

To test the second hypothesis, we reestimated import demand elasticities at the industry level, through a concordance linking HS six digit classification to ISIC three digit industry classification. Table 3 provides the average elasticity by country at the different levels of aggregation. It confirms that elasticities are smaller in magnitude when estimated at the industry level than at the tariff line level. On average elasticities estimated at the six digit level of the HS are 39 percent higher than those estimated at the three digit level of the ISIC.

In order to test the last two hypothesis we run the average elasticity at the country level on log of GDP and GDP per capita. The conditional plots of these relationships are provided in Figures 3 and 4 , as well as the estimated coefficient and its standard error. They confirm that import demand is more elastic in large and less developed countries. Thus, the last two hypotheses cannot 
be rejected. ${ }^{12}$

\section{Calculating TRIs and Deadweight Losses}

The estimated import demand elasticities allow us to examine the trade restrictiveness and welfare losses associated with the existing tariff structure in 88 countries in our sample for which tariff schedules are available. ${ }^{13}$ More importantly, this can be done within a theoretically-sound framework. The literature has traditionally measure trade restrictiveness using a-theoretical measures such as simple and import-weigthed tariffs. ${ }^{14}$ As argued by Anderson and Neary $(1992,1994,2003)$ these have little theoretical foundations. Import-weighted averages tend to be downward bias, as for example, they put zero weight on prohibitive tariffs and simple average tariffs put identical weights on tariffs that may have very different economic significance. Anderson and Neary (1992, 1994) propose a trade restrictiveness index (TRI), which has a theoretically sound averaging procedure. TRI is defined as the uniform tariff that yields the same real income, and therefore national welfare, as the existing tariff structure. Deadweight loss measures can also be constructed using TRIs and theoretically consistent estimates of import demand elasticities, which in turn allows for comparisons of welfare distortions associated with each country's tariff structure.

To calculate the TRI, one would ideally need to solve a full-fledged general equilibrium model for the uniform tariff that could keep welfare constant given the observed tariff structure. Feenstra (1995) provides a simplification of TRI, which only requires information on import demand elasticities, share of imports and the current tariff schedule. The major drawback of such simplification is that it ignores the general equilibrium of cross price effects. Nonetheless, as an illustration of the first order effect of trade distortions, the simplified TRI is informative: ${ }^{15}$

\footnotetext{
${ }^{12}$ We found similar patterns when regressing on the median elasticity by country. The coefficient on GDP is 0.03 and on GDP per capita - 0.02 and both are statistically significant at the 1 percent leve.

${ }^{13}$ Data sources for tariff data are United Nations' Comtrade and the Integrated Database of the WTO. In this paper, we abstract from measuring the trade restrictiveness of non-tariff barriers, as well as the role of tariff preferences in eroding trade restrictiveness. For an attempt to do so, see Kee, Nicita and Olarreaga (2004b).

${ }^{14}$ If NTB measures are to be considered, trade economist often use simple or import-weigthed coverage ratios of NTBs.

${ }^{15}$ See Equation (3.5) in Feenstra (1995). Note that given our setup, the derivation in Feenstra (1995) is equivalent to deriving the TRI that would keep GDP at its maximum level given the existing tariff structure.
} 


$$
\operatorname{TRI}_{c}=\left[\frac{\frac{1}{2} \sum_{n}\left(d q_{n, c} / d p_{n, c}\right) t_{n, c}^{2}}{\frac{1}{2} \sum_{n}\left(d q_{n, c} / d p_{n, c}\right)}\right]^{1 / 2}=\left[\frac{\frac{1}{2} \sum_{n} s_{n} \varepsilon_{n n} t_{n c}^{2}}{\frac{1}{2} \sum_{n} s_{n} \varepsilon_{n n}}\right]^{1 / 2}
$$

where $t_{n c}$ is the tariff on good $n$ in country $c$. Thus, the simplified TRI is the squared root of a weighted average of squared tariffs, where weights are determined by the import demand elasticities in each country. Given that tariffs are squared in Equation (26), $\mathrm{TRI}_{c}$ depends not only on the weighted average level of tariffs, but also its variance. In other words, high dispersion of $t_{n c}$ increases $\mathrm{TRI}_{c}$, for a given weighted average; see Anderson and Neary (2004) for a thorough discussion of the importance of tariff dispersion when measuring trade restrictiveness.

Note that the numerator in Equation (26) is equal to the share in GDP of the deadweight loss (DWL) associated with the existing tariff structure:

$$
\begin{aligned}
\frac{\mathrm{DWL}_{c}}{\mathrm{GDP}_{c}} & =\frac{1}{2} \sum_{n} s_{n} \varepsilon_{n n} t_{n c}^{2}=\frac{1}{2}\left(\mathrm{TRI}_{c}\right)^{2} \sum_{n} s_{n} \varepsilon_{n n}, \text { or } \\
\mathrm{DWL}_{c} & =\frac{1}{2}\left(\mathrm{TRI}_{c}\right)^{2} \mathrm{GDP}_{c} \sum_{n} s_{n} \varepsilon_{n n} .
\end{aligned}
$$

Thus, with information on the current tariff schedule, import shares and import demand elasticities, we can construct both $\mathrm{TRI}_{c}$ and $\mathrm{DWL}_{c}$. Given that we are using GDP maximizing import demand elasticities instead of Hicksian elasticities as in Feenstra (1995), our measures of TRI and DWL are consistent with GDP maximization. ${ }^{16}$

Results using Equations (26) and (27) are provided in Table 4. Table 4 also shows simple and import-weighted average tariffs, as well as the variance of tariffs for 88 countries. The sample mean average tariffs, import-weighted tariffs and TRI are 10.04, 8.95 and 13.15. The three indicators of trade restrictiveness are highly correlated: the correlation coefficient between TRI and the two other measures is 0.91 , and the correlation between the simple average tariff and the import-weighted tariff is 0.96 . Figure 5 provides a plot of TRIs versus simple average tariffs for the 88 countries in our sample. Observations tend to be above the 45 degree dotted line, which suggests that average tariffs tend to underestimate the degree of trade restrictiveness as defined by the TRI. Overall, both simple and weighted average tariffs tend to underestimate TRI by about 30 percent. The countries where underestimation is the largest are Estonia (EST), Norway (NOR), Sudan (SDN),

\footnotetext{
${ }^{16}$ See Kohli (1991), Equations 18.27 to 18.31 .
} 
Oman (OMN), and the United States (USA). The magnitude of underestimation in these countries is more than 70 percent. Among these countries, Norway, Sudan and the United States also have very high variances as shown in Table 4 which explains the relatively large TRIs. Countries that have the largest TRIs include India (IND), Morocco (MAR) and Tunisia (TUN).

To facilitate cross country comparison of trade distortion, Table 4 also provides DWL estimates in millions of US dollars. United States, China, Mexico, India and Germany are the countries in the sample with the largest losses associated with their existing tariff structure. In particular, at $\$ 7$ billion per year, the DWL of the United States is more than a quarter of the sum of welfare losses in our sample. Moreover, given that the TRI of the US presented in Table 4 is significantly higher than the average tariff, the US deadweight loss estimate is larger then Feenstra's (1992), who found that the welfare loss in the US associated with an average tariff of 3.7 percent was in the range of $\$ 1.2$ to 3.4 billion in 1985 .

A few caveats. First, this version of TRI and DWL calculations only take into account the direct own price effects of tariffs. They ignore the cross price effects of other tariffs on import demand. Thus, at best, it represents the first order impact of import demand and welfare due to tariffs. Second, the calculation of TRI and DWL ignore the existence of non-tariff barriers, such as quotas. To the extent that non-tariff barriers are the more binding constraints in distorting imports, TRI and DWL presented here may only capture the lower bound of the nature of trade protections and welfare distortions. Third, we have focused on most favored nation's tariffs, ignoring the numerous preferential agreements that may erode trade restrictiveness. Fourth, given the static nature of our analysis, dynamics effects associated with tariffs are ignored. Finally, we only include positive import in the calculation of TRI and DWL. This ignores prohibitive tariffs. To correct for this, we re-calculated TRI and DWL according to the following specification, where we assume the demand for goods that have zero import has a slope of $a_{n n}$ :

$$
\mathrm{TRI}_{c}^{*}=\left[\frac{\sum_{n}\left(a_{n n}+s_{n, c}^{2}-s_{n, c}\right) t_{n, c}^{2}}{\sum_{n}\left(a_{n n}+s_{n, c}^{2}-s_{n, c}\right)}\right]^{1 / 2}
$$

This out of sample prediction does not change our results. While TRI* tend to be slightly smaller than $\mathrm{TRI}_{c}$, the two TRI's series have a correlation coefficient of 0.99 . This suggests that if the restrictiveness of prohibitive tariffs on a particular good is (by definition) infinite, their impact on 
the overall trade restrictiveness is marginal in our sample.

\section{Concluding Remarks}

A set of consistently estimated import demand elasticities at the tariff line level is critical to understand the consequences of trade liberalization. This paper is the first attempt to provide a theoretically consistent methodology to estimate import demand elasticities for a wide variety of countries at the six digit level of the HS (4,625 tariff lines). Moreover, the methodology can be easily implemented with existing trade data.

We find that the sample average import demand elasticities is -1.67 , while the sample median is -1.08. There is wide variation in import demand elasticities across countries and tariff lines, and the estimates exhibit some interesting patterns. First, homogeneous goods have more elastic import demand than differentiated goods. Second, the average estimated elasticities decrease as we increase the level of aggregation at which they are estimated. Third, large countries tend to have more elastic import demands. Fourth, more developed countries tend to have less elastic import demand.

In addition, we calculate trade restrictiveness indices (TRIs) and welfare losses associated with the existing tariff structures for 88 countries. We use a methodology that is both theoretically sound, and more importantly consistent with our estimated elasticities. Results show that both simple and weighted average tariffs tend to underestimate the distortion imposed by the tariff regime by 30 percent on average. Because of the large variance in the United States tariff schedule, underestimation of trade restrictiveness is among the largest. The simple and import-weighted tariffs in the United States are around 4 percent, whereas the TRI is close to 15 percent. With welfare losses at around $\$ 7$ billion per year, the United States is the country in our sample whose tariff structure imposes the largest welfare costs on its nationals. It is followed by China, Mexico, India and Germany. Finally, given the high TRI of the US, the $\$ 7$ billion per year deadweight loss estimate is also larger then previous findings of the literature which mainly use average tariffs. 


\section{References}

[1] Anderson, James and Peter Neary (1992), "Trade reforms with quotas, partial rent retention and tariffs", Econometrica 60(1), 57-76.

[2] Anderson, James and Peter Neary (1994), "Measuring the restrictiveness of trade policies", World Bank Economic Review 8 (2), 151-169.

[3] Anderson, James and Peter Neary (2003), "The Mercantilist index of trade policy", International Economic Review 44(2), 627-649.

[4] Anderson, James and Peter Neary (2004), "Welfare versus market access: the implications of tariff structure for tariff reform", NBER working paper \#10730.

[5] Athukorola, P. and J. Riedel (1994), "Demand and supply factors in the determination of NIE exports: a simultaneous error-correction model for Hong Kong: a comment," Economic Journal 105, 1411-1414.

[6] Blonigen, Bruce and Wesley Wilson (1999), "Explaining Armington: What determines substitutability between home and foreign goods", Canadian Journal of Economics 32(1), 1-21.

[7] Broda, Christian and David Weinstein (2003), "Globalization and the gains from variety", mimeo.

[8] Caves, Douglas W., Laurits R. Christensen, and Erwin Diewert (1982), "Multilateral Comparisons of Output, Input, and Productivity using Superlative Index Numbers," Economic Journal 92, 73-86.

[9] Feenstra, Robert (1992), "How costly is protectionism?", Journal of Economic Perspectives, 6, 159-178.

[10] Feenstra, Robert (1995), "Estimating the effects of trade policy", in Gene Grossman and Kenneth Rogoff, eds., Handbook of International Economics, vol. 3, Elsevier, Amsterdam.

[11] Gallaway, Michael, Christine McDaniel and Sandra Rivera (2003), "Short-run and long-run industry-level estimates of US Armington elasticities", North American Journal of Economics and Finance 14, 49-68. 
[12] Harrigan, James (1997), "Technology, Factor Supplies, and International Specialization: Estimating the Neoclassical Model," The American Economic Review 87 (4), 475-494.

[13] Hsiao, Cheng (1986), Analysis of panel data, Cambridge University Press.

[14] Kee, Hiau Looi, Alessandro Nicita and Marcelo Olarreaga (2004), "Estimating Multilateral Trade Restrictiveness Indices", mimeo, The World Bank.

[15] Kee, Hiau Looi, Alessandro Nicita and Marcelo Olarreaga (2004b), "Estimating Ad-valorem equivalents of Non-Tariff Barriers", mimeo, The World Bank.

[16] Kohli, Ulrich (1991), Technology, Duality, and Foreign Trade: The GNP Function Approach to Modeling Imports and Exports, The University of Michigan Press, Ann Arbor.

[17] Leamer, Edward (1974), "National tariff averages with estimated weights", Southern Economic Journal 41(1), 34-46.

[18] Marquez, Jaime (1999), "Long-period stable trade elasticities for Canada, Japan, and the United States", Review of International Economics 7, 102-116.

[19] Marquez, Jaime (2002), Estimating trade elasticities, Kluwer, Boston.

[20] Marquez, Jaime (2003), "US imports", mimeo, presented at the AEA meetings in January 2004.

[21] Panagariya, Arvind, Shekhar Shah and Deepak Mishra (2001), "Demand elasticities in international trade: are they really low?" Journal of Development Economics 64, 313-342.

[22] Rauch, James (1999), "Network versus markets in international trade", Journal of International Economics 48, 7-35.

[23] Riedel, J. (1988), "The demand for LDC exports of manufactures: estimates for Hong Kong," Economic Journal 98, 138-148.

[24] Schott, Peter (2004), "Across-Product versus Within-Product Specialization in International Trade," Quarterly Journal of Economics, forthcoming 
[25] Shiells, Clinton, Robert Stern and Alan Deardorff (1987), "Estimates of the elasticities of substitution between imports and home goods for the United States," Weltwirtschtarchives, $122,497-519$.

[26] Shiells, Clinton, David Roland-Holst and Kenneth Reinert (1993), "Modeling a North American Free Trade Area: Estimation of flexible functional forms", Welwirtschaftliches Archiv 129, $55-77$.

[27] Stern et al (1976), Price elasticities in international trade : an annotated bibliography, London.

[28] Winters, Alan (1984), "Separability and the specification of foreign trade functions," Journal of International Economics 17, 239-263.

[29] Kei-Mu Yi (2003), "Can vertical specialization explain the growth of world trade?", Journal of Political Economy 111, 52-102. 


\section{A From $N$ to 2 good-economies}

This section constructs $N$ two good economies from a $N$ good economy. Consider a small economy producing $N$ goods. The share equation of industry $n$ is given by:

$$
s_{n}^{t}\left(p^{t}, v^{t}\right)=a_{0 n}^{t}+a_{n n}^{t} \ln p_{n}^{t}+\sum_{k \neq n, k=1}^{N} a_{n k}^{t} \ln p_{k}^{t}+\sum_{m=1}^{M} c_{n m}^{t} \ln v_{m}^{t} .
$$

Given the translog GDP function, if all the translog parameters are time invariant, then the exact price index of the GDP function is a Tornqvist index (Caves, Christensen and Diewert, 1983):

$$
\begin{aligned}
\ln P^{t} & =\sum_{k=1}^{N} \bar{s}_{k}^{t} \ln p_{k}^{t}, \\
& =\bar{s}_{n}^{t} \ln p_{n}^{t}+\left(1-\bar{s}_{n}^{t}\right) \ln p_{-n}^{t}, \text { with } \\
\bar{s}_{k}^{t} & =\frac{1}{2}\left(s_{k}^{t}+s_{k}^{t-1}\right), \forall k, \text { and } \\
\ln p_{-n}^{t} & =\frac{1}{1-\bar{s}_{n}^{t}} \sum_{k \neq n, k=1}^{N} \bar{s}_{k}^{t} \ln p_{k}^{t}, \forall n,
\end{aligned}
$$

where $\ln p_{-n}^{t}$ is the non-good- $n$ price index, which is the aggregate Tornqvist price index of all goods excluding good $n$. Notice that in Equation (32) we imposed the restriction that $\sum_{n=1}^{N} \bar{s}_{n}^{t}=1$.

Substituting Equation (32) into Equation (28), and further assuming that all the parameters of the GDP function are time invariant yields:

$$
s_{n}^{t}\left(p^{t}, v^{t}\right)=a_{0 n}+a_{n n} \ln p_{n}^{t}+a_{n-n} \ln p_{-n}^{t}+\sum_{m=1}^{M} c_{n m} \ln v_{m}^{t},
$$

This requires

$$
\begin{aligned}
a_{n-n} \ln p_{-n}^{t} & \equiv \sum_{k \neq n, k=1}^{N} a_{n k}^{t} \ln p_{k}^{t} \Rightarrow \\
a_{n-n} \frac{1}{1-\bar{s}_{n}^{t}} \sum_{k \neq n, k=1}^{N} \bar{s}_{k}^{t} \ln p_{k}^{t} & \equiv \sum_{k \neq n, k=1}^{N} a_{n k}^{t} \ln p_{k}^{t} \Rightarrow \\
a_{n-n} \frac{\bar{s}_{k}^{t}}{1-\bar{s}_{n}^{t}} & \equiv a_{n k}, \forall n, k .
\end{aligned}
$$

Homogeneity of degree zero in prices implies $\sum_{k=1}^{N} a_{n k}=0, \forall n$. Equation (33) implies the following 
is necessary true:

$$
\begin{aligned}
a_{n-n} & \equiv-a_{n n}, \text { or } \\
s_{n}^{t}\left(p^{t}, v^{t}\right) & =a_{0 n}+a_{n n} \ln \frac{p_{n}^{t}}{p_{-n}^{t}}+\sum_{m=1}^{M} c_{n m} \ln v_{m}^{t} .
\end{aligned}
$$

which completes the illustration of how we can reduce an $N$-good economy into a two-good economy, with the appropriate construction of the price index $\ln p_{-n}^{t}$.

\section{B Aggregating elasticities to the industry level}

Our estimation procedure in Section 3 could be applied to goods at any level of aggregation, provided the adequate price indices have been constructed. This section provides an aggregation procedure from six digit HS estimates to any higher level of aggregation for a translog GDP function.

Let good $n \in A$ belong to industry $A$ and good $n \in B$ belong to industry $B$, and $A \cup B=$ $\{1, \ldots, N\}, A, B \neq \varnothing$. Then, the shares of good $n$ and industry $A$ in GDP are given by:

$$
\begin{aligned}
s_{n}^{t}\left(p^{t}, v^{t}\right) & =a_{0 n}^{t}+\sum_{k=1}^{N} a_{n k}^{t} \ln p_{k}^{t}+\sum_{m=1}^{M} c_{n m}^{t} \ln v_{m}^{t}, \\
s_{A}^{t} & \equiv \sum_{n \in A} s_{n}^{t}\left(p^{t}, v^{t}\right) \\
& =\sum_{n \in A} a_{0 n}^{t}+\sum_{k \in A} a_{n k}^{t} \ln p_{k}^{t}+\sum_{k \in B} a_{n k}^{t} \ln p_{k}^{t}+\sum_{k \in A} \sum_{m=1}^{M} c_{n m}^{t} \ln v_{m}^{t} .
\end{aligned}
$$

As shown in Equation (29), the Tornqvist price index at the industry level is the weighted average of goods' price indices within each industry:

$$
\begin{aligned}
& \ln p_{A}^{t}=\frac{1}{1-\bar{s}_{A}^{t}} \sum_{n \in A} \bar{s}_{n}^{t} \ln p_{n}^{t} \\
& \ln p_{B}^{t}=\frac{1}{1-\bar{s}_{B}^{t}} \sum_{n \in B} \bar{s}_{n}^{t} \ln p_{n}^{t}
\end{aligned}
$$

where $\bar{s}^{t}$ denotes the average share between two consecutive periods. To apply the above Tornqvist price index, we need to assume that all the translog parameters $a_{n k}^{t}$ are time invariant.

If we were to estimate our parameters at the industry level instead of the good level, the share equation of industry $A$ would be given by:

$$
s_{A}^{t}=a_{0 A}+a_{A A} \ln p_{A}^{t}+a_{A B} \ln p_{B}^{t}+\sum_{m=1}^{M} c_{A m}^{t} \ln v_{m}^{t} .
$$


Equating Equations (34) and (36) imply that

$$
\begin{aligned}
a_{0 A} & \equiv \sum_{n \in A} a_{0 n}, \text { and }, \\
a_{A A} \ln p_{A}^{t} & \equiv \sum_{k \in A} a_{n k} \ln p_{k}^{t} \Rightarrow \\
\frac{a_{A A}}{1-\bar{s}_{A}^{t} \bar{s}_{n}^{t}} & =a_{n k} \forall n, k \in A, \\
a_{A A} & =\sum_{k \in A} a_{n k} \neq 0, \because B \neq \varnothing .
\end{aligned}
$$

From Section 2, we know that

$$
\begin{aligned}
\varepsilon_{A A}^{t} & =\frac{a_{A A}}{s_{A}^{t}}+s_{A}^{t}-1 \Rightarrow \\
& =\frac{\sum_{k \in A} a_{n k}}{s_{A}^{t}}+s_{A}^{t}-1
\end{aligned}
$$

We also know from Equation (33) that

$$
\begin{aligned}
a_{n k} & =-a_{n n} \frac{s_{k}^{t}}{1-s_{n}^{t}} \Rightarrow \\
\sum_{k \in A} a_{n k} & =a_{n n} \frac{1-s_{A}^{t}}{1-s_{n}^{t}} .
\end{aligned}
$$

Thus the industry elasticity is given by:

$$
\varepsilon_{A A}^{t}=\frac{1-s_{A}^{t}}{s_{A}^{t}} \sum_{n \in A} \frac{a_{n n}}{1-s_{n}^{t}}+s_{A}^{t}-1 .
$$

It can be further shown that the price elasticity of an industry is the weighted average of the own and cross price elasticities of all goods within the industry:

$$
\varepsilon_{A A}^{t}=\frac{1}{s_{A}^{t}} \sum_{n \in A} \sum_{k \in A} s_{n}^{t} \varepsilon_{n k}^{t} .
$$


Table 1: Estimated elasticities: sample moments by country

\begin{tabular}{|c|c|c|c|c|c|c|c|c|c|}
\hline Country & $\begin{array}{l}\text { Simple } \\
\text { Average }\end{array}$ & $\begin{array}{l}\text { Standard } \\
\text { Deviation }\end{array}$ & Median & $\begin{array}{c}\text { Import } \\
\text { weighted } \\
\text { average }\end{array}$ & Country & $\begin{array}{l}\text { Simple } \\
\text { Average }\end{array}$ & $\begin{array}{l}\text { Standard } \\
\text { Deviation }\end{array}$ & Median & $\begin{array}{c}\text { Import } \\
\text { weighted } \\
\text { average }\end{array}$ \\
\hline Albania (ALB) & -1.12 & -1.04 & -1.04 & -1.06 & Italy (ITA) & -2.1 & -1.06 & -1.07 & -1.14 \\
\hline United Arab Em. (ARE) & -1.38 & -1.16 & -1.11 & -1.07 & Jamaica (JAM) & -1.16 & -1.1 & -1.08 & -1.05 \\
\hline Argentina (ARG) & -2.52 & -1.13 & -1.15 & -1.26 & Jordan (JOR) & -1.16 & -1.05 & -1.07 & -1.04 \\
\hline Armenia (ARM) & -1.09 & -1.06 & -1.06 & -1.05 & Japan (JPN) & -4.05 & -1.23 & -1.4 & -1.37 \\
\hline Australia (AUS) & -2.49 & -1.1 & -1.1 & -1.19 & Kenya (KEN) & -1.26 & -1.14 & -1.1 & -1.07 \\
\hline Austria (AUT) & -1.8 & -1.05 & -1.04 & -1.08 & Korea (KOR) & -2.08 & -1.1 & -1.1 & -1.1 \\
\hline Azerbaijan (AZE) & -1.18 & -1.11 & -1.1 & -1.07 & Lebanon (LBN) & -1.26 & -1.03 & -1.02 & -1.06 \\
\hline Burundi (BDI) & -1.07 & -1.19 & -1.12 & -1.05 & Sri Lanka (LKÁ) & -1.2 & -1.1 & -1.04 & -1.06 \\
\hline Belgium (BEL) & -1.51 & -1.04 & -1.05 & -1.05 & Lithuania (LTU) & -1.2 & -1.03 & -1.02 & -1.06 \\
\hline Benin (BEN) & -1.11 & -1.11 & -1.11 & -1.05 & Latvia (LVA) & -1.16 & -1.03 & -1.02 & -1.05 \\
\hline Burkina Faso (BFA) & -1.1 & -1.12 & -1.08 & -1.05 & Morocco (MAR) & -1.45 & -1.1 & -1.05 & -1.09 \\
\hline Bangladesh (BGD) & -1.65 & -1.2 & -1.19 & -1.15 & Madagascar (MDG) & -1.17 & -1.12 & -1.18 & -1.09 \\
\hline Bulguria (BGR) & -1.18 & -1.05 & -1.04 & -1.06 & Maldives (MDV) & -1.04 & -1.04 & -1.03 & -1.02 \\
\hline Belarus (BLR) & -1.17 & -1.04 & -1.05 & -1.05 & Mexico (MEX) & -2.08 & -1.06 & -1.07 & -1.11 \\
\hline Belize (BLZ) & -1.03 & -1.05 & -1.03 & -1.03 & Macedonia (MKD) & -1.12 & -1.04 & -1.05 & -1.05 \\
\hline Bolivia (BOL) & -1.23 & -1.07 & -1.1 & -1.08 & Mali (MLI) & -1.15 & -1.19 & -1.09 & -1.06 \\
\hline Brazil (BRA) & -3.38 & -1.3 & -1.22 & -1.34 & Malta (MLT) & -1.09 & -1.04 & -1.02 & -1.04 \\
\hline Barbados (BRB) & -1.08 & -1.04 & -1.08 & -1.04 & Mongolia (MNG) & -1.05 & -1.06 & -1.07 & -1.03 \\
\hline Central Afr. Rep. (CAF) & -1.08 & -1.15 & -1.11 & -1.05 & Mauritius (MUS) & -1.11 & -1.05 & -1.02 & -1.05 \\
\hline Canada (CAN) & -2.29 & -1.05 & -1.05 & -1.13 & Malawi (MWI) & -1.07 & -1.11 & -1.13 & -1.04 \\
\hline Switzerland (CHE) & -1.99 & -1.07 & -1.06 & -1.1 & Malaysia (MYS) & -1.45 & -1.07 & -1.06 & -1.05 \\
\hline Chile (CHL) & -1.61 & -1.05 & -1.08 & -1.1 & Niger (NER) & -1.12 & -1.1 & -1.18 & -1.06 \\
\hline China $(\mathrm{CHN})$ & -2.54 & -1.12 & -1.14 & -1.13 & Nigeria (NGA) & -1.59 & -1.29 & -1.15 & -1.11 \\
\hline Cote d'Ivoire (CIV) & -1.32 & -1.16 & -1.13 & -1.08 & Nicaragua (NIC) & -1.06 & -1.06 & -1.07 & -1.03 \\
\hline Cameroon (CMR) & -1.36 & -1.21 & -1.15 & -1.12 & Netherlands (NLD) & -1.66 & -1.04 & -1.04 & -1.07 \\
\hline Congo (COG) & -1.13 & -1.11 & -1.09 & -1.04 & Norway (NOR) & -1.93 & -1.06 & -1.08 & -1.11 \\
\hline Colombia (COL) & -1.81 & -1.13 & -1.08 & -1.16 & New Zealand (NZL) & -1.56 & -1.11 & -1.07 & -1.1 \\
\hline Comorros (COM) & -1.04 & -1.17 & -1.08 & -1.03 & $\mathrm{Oman}(\mathrm{OMN})$ & -1.23 & -1.05 & -1.06 & -1.05 \\
\hline Costa Rica (CRI) & -1.23 & -1.03 & -1.04 & -1.06 & Panama (PAN) & -1.24 & -1.05 & -1.09 & -1.07 \\
\hline Cyprus (CYP) & -1.17 & -1.03 & -1.02 & -1.05 & Peru (PER) & -1.74 & -1.18 & -1.11 & -1.16 \\
\hline Czech Rep. (CZE) & -1.36 & -1.03 & -1.04 & -1.05 & Philippines (PHL) & -1.61 & -1.08 & -1.06 & -1.07 \\
\hline Germany (DEU) & -2.01 & -1.06 & -1.07 & -1.14 & Poland (POL) & -1.51 & -1.08 & -1.04 & -1.09 \\
\hline Denmark (DNK) & -1.69 & -1.09 & -1.07 & -1.11 & Portugal (PRT) & -1.47 & -1.05 & -1.03 & -1.09 \\
\hline Algeria (DZA) & -1.59 & -1.13 & -1.14 & -1.1 & Paraguay (PRY) & -1.19 & -1.06 & -1.02 & -1.07 \\
\hline Egypt (EGY) & -1.78 & -1.14 & -1.13 & -1.12 & Romania (ROM) & -1.37 & -1.04 & -1.06 & -1.09 \\
\hline Spain (ESP) & -1.95 & -1.06 & -1.05 & -1.14 & Rwanda (RWA) & -1.12 & -1.13 & -1.14 & -1.07 \\
\hline Estonia (EST) & -1.09 & -1.03 & -1.02 & -1.03 & Saudi Arabia (SAU) & -1.86 & -1.04 & -1.06 & -1.13 \\
\hline Ethiopia (ETH) & -1.17 & -1.09 & -1.06 & -1.07 & Sudan (SDN) & -1.32 & -1.15 & -1.14 & -1.08 \\
\hline Finland (FIN) & -1.84 & -1.07 & -1.06 & -1.12 & Senegal (SEN) & -1.16 & -1.08 & -1.11 & -1.05 \\
\hline France (FRA) & -1.93 & -1.05 & -1.07 & -1.14 & Singapore (SGP) & -1.3 & -1.06 & -1.02 & -1.04 \\
\hline Gabon (GAB) & -1.15 & -1.11 & -1.12 & -1.08 & El Salvador (SLV) & -1.25 & -1.06 & -1.08 & -1.07 \\
\hline United Kingdom (GBR) & -1.91 & -1.07 & -1.06 & -1.13 & Surinam (SUR) & -1.02 & -1.05 & -1.04 & -1.02 \\
\hline Georgia (GEO) & -1.15 & -1.13 & -1.09 & -1.05 & Slovakia (SVK) & -1.22 & -1.03 & -1.02 & -1.05 \\
\hline Ghana (GHA) & -1.15 & -1.05 & -1.07 & -1.05 & Slovenia (SVN) & -1.24 & -1.03 & -1.03 & -1.05 \\
\hline Guinea (GIN) & -1.19 & -1.12 & -1.1 & -1.08 & Sweden (SWE) & -2.01 & -1.06 & -1.07 & -1.11 \\
\hline Gambia (GMB) & -1.04 & -1.05 & -1.06 & -1.04 & Togo $(\mathrm{TGO})$ & -1.08 & -1.05 & -1.06 & -1.04 \\
\hline Greece (GRC) & -1.71 & -1.04 & -1.03 & -1.12 & Thailand (THA) & -1.83 & -1.15 & -1.08 & -1.08 \\
\hline Guatemala (GTM) & -1.38 & -1.09 & -1.14 & -1.09 & Trinidad T. (TTO) & -1.15 & -1.07 & -1.07 & -1.06 \\
\hline Guyana (GUY) & -1.03 & -1.04 & -1.04 & -1.02 & Tunisia (TUN) & -1.24 & -1.04 & -1.06 & -1.06 \\
\hline Hong Kong (HKG) & -1.57 & -1.04 & -1.02 & -1.04 & Turkey (TUR) & -1.97 & -1.11 & -1.09 & -1.14 \\
\hline Honduras (HND) & -1.11 & -1.05 & -1.09 & -1.04 & Tanzania (TZA) & -1.28 & -1.09 & -1.09 & -1.11 \\
\hline Croatia (HRV) & -1.22 & -1.04 & -1.02 & -1.07 & Uganda (UGA) & -1.22 & -1.08 & -1.17 & -1.09 \\
\hline Hungary (HUN) & -1.32 & -1.06 & -1.05 & -1.06 & Ukraine (UKR) & -1.46 & -1.05 & -1.06 & -1.1 \\
\hline Indonesia (IDN) & -2.09 & -1.12 & -1.13 & -1.14 & Uruguay (URY) & -1.4 & -1.08 & -1.1 & -1.12 \\
\hline India (IND) & -3.26 & -1.31 & -1.38 & -1.33 & United States (USA) & -3.39 & -1.1 & -1.16 & -1.3 \\
\hline Ireland (IRL) & -1.51 & -1.04 & -1.05 & -1.07 & Venezuela (VEN) & -1.85 & -1.09 & -1.12 & -1.15 \\
\hline Iran (IRN) & -1.87 & -1.13 & -1.15 & -1.11 & South Africa (ZAF) & -2.04 & -1.14 & -1.1 & -1.16 \\
\hline Iceland (ISL) & -1.2 & -1.04 & -1.07 & -1.07 & Zambia (ZMB) & -1.12 & -1.06 & -1.09 & -1.05 \\
\hline Israel (ISR) & -1.13 & -1.06 & -1.03 & -1.06 & & & & & \\
\hline
\end{tabular}


Table 2: Sample moments of the estimated import demand elasticity by Rauch classification $^{a}$

\begin{tabular}{lccc}
\hline & Mean & Median & Standard Deviation \\
\hline Differentiated goods & -1.59 & -1.07 & 2.25 \\
Referenced price & -1.84 & -1.09 & 2.84 \\
Homogeneous goods & -1.98 & -1.09 & 3.32 \\
\hline
\end{tabular}

${ }^{a}$ The HS six digit schedule is first filtered into the four digit SITC schedule which Rauch (1999) used to classify goods. Homogenous goods are those traded on organized exchanges. Reference priced goods are those listed as having a reference price, and differentiated goods are goods that cannot not be priced by either of these two means. 
Table 3: Average Estimated elasticities at different levels of aggregation $^{a}$

\begin{tabular}{|c|c|c|c|c|c|}
\hline Country & HS six digit & ISIC three digit & Country & HS six digit & ISIC three digit \\
\hline ALB & -1.12 & -1.04 & ITA & -2.10 & -1.06 \\
\hline A RE & -1.38 & -1.16 & JA M & -1.16 & -1.10 \\
\hline A RG & -2.52 & -1.13 & JOR & -1.16 & -1.05 \\
\hline ARM & -1.09 & -1.06 & JP N & -4.05 & -1.23 \\
\hline AUS & -2.49 & -1.10 & KEN & -1.26 & -1.14 \\
\hline A U T & -1.80 & -1.05 & KOR & -2.08 & -1.10 \\
\hline $\mathbf{A} Z \mathbf{E}$ & -1.18 & -1.11 & LBN & -1.26 & -1.03 \\
\hline B D I & -1.07 & -1.19 & LKA & -1.20 & -1.10 \\
\hline B EL & -1.51 & -1.04 & LT U & -1.20 & -1.03 \\
\hline BEN & -1.11 & -1.11 & LVA & -1.16 & -1.03 \\
\hline BFA & -1.10 & -1.12 & M A R & -1.45 & -1.10 \\
\hline B GD & -1.65 & -1.20 & MDG & -1.17 & -1.12 \\
\hline B G R & -1.18 & -1.05 & MDV & -1.04 & -1.04 \\
\hline B L R & -1.17 & -1.04 & MEX & -2.08 & -1.06 \\
\hline B L Z & -1.03 & -1.05 & M KD & -1.12 & -1.04 \\
\hline BOL & -1.23 & -1.07 & MLI & -1.15 & -1.19 \\
\hline B RA & -3.38 & -1.30 & MLT & -1.09 & -1.04 \\
\hline B R B & -1.08 & -1.04 & MNG & -1.05 & -1.06 \\
\hline C A F & -1.08 & -1.15 & MUS & -1.11 & -1.05 \\
\hline CAN & -2.29 & -1.05 & M W I & -1.07 & -1.11 \\
\hline CHE & -1.99 & -1.07 & MYS & -1.45 & -1.07 \\
\hline CHL & -1.61 & -1.05 & NER & -1.12 & -1.10 \\
\hline CHN & -2.54 & -1.12 & NGA & -1.59 & -1.29 \\
\hline CIV & -1.32 & -1.16 & NIC & -1.06 & -1.06 \\
\hline CMR & -1.36 & -1.21 & NLD & -1.66 & -1.04 \\
\hline $\mathrm{COG}$ & -1.13 & -1.11 & NOR & -1.93 & -1.06 \\
\hline COL & -1.81 & -1.13 & NZL & -1.56 & -1.11 \\
\hline COM & -1.04 & -1.17 & OMN & -1.23 & -1.05 \\
\hline CRI & -1.23 & -1.03 & PAN & -1.24 & -1.05 \\
\hline CYP & -1.17 & -1.03 & PER & -1.74 & -1.18 \\
\hline $\mathrm{CZE}$ & -1.36 & -1.03 & PHL & -1.61 & -1.08 \\
\hline DEU & -2.01 & -1.06 & POL & -1.51 & -1.08 \\
\hline D NK & -1.69 & -1.09 & PRT & -1.47 & -1.05 \\
\hline D Z A & -1.59 & -1.13 & P RY & -1.19 & -1.06 \\
\hline EG Y & -1.78 & -1.14 & ROM & -1.37 & -1.04 \\
\hline ESP & -1.95 & -1.06 & RWA & -1.12 & -1.13 \\
\hline EST & -1.09 & -1.03 & SA U & -1.86 & -1.04 \\
\hline ЕTH & -1.17 & -1.09 & SD N & -1.32 & -1.15 \\
\hline F IN & -1.84 & -1.07 & SEN & -1.16 & -1.08 \\
\hline FRA & -1.93 & -1.05 & SGP & -1.30 & -1.06 \\
\hline G A B & -1.15 & -1.11 & SLV & -1.25 & -1.06 \\
\hline G B R & -1.91 & -1.07 & SUR & -1.02 & -1.05 \\
\hline GEO & -1.15 & -1.13 & SVK & -1.22 & -1.03 \\
\hline G H A & -1.15 & -1.05 & SVN & -1.24 & -1.03 \\
\hline G IN & -1.19 & -1.12 & SWE & -2.01 & -1.06 \\
\hline GMB & -1.04 & -1.05 & TGO & -1.08 & -1.05 \\
\hline GRC & -1.71 & -1.04 & THA & -1.83 & -1.15 \\
\hline G T M & -1.38 & -1.09 & T TO & -1.15 & -1.07 \\
\hline G UY & -1.03 & -1.04 & T UN & -1.24 & -1.04 \\
\hline H K G & -1.57 & -1.04 & TUR & -1.97 & -1.11 \\
\hline HND & -1.11 & -1.05 & T Z A & -1.28 & -1.09 \\
\hline H RV & -1.22 & -1.04 & U G A & -1.22 & -1.08 \\
\hline HUN & -1.32 & -1.06 & U K R & -1.46 & -1.05 \\
\hline ID N & -2.09 & -1.12 & U RY & -1.40 & -1.08 \\
\hline IN D & -3.26 & -1.31 & US A & -3.39 & -1.10 \\
\hline IR L & -1.51 & -1.04 & VEN & -1.85 & -1.09 \\
\hline IR N & -1.87 & -1.13 & $\mathrm{ZAF}$ & -2.04 & -1.14 \\
\hline IS L & -1.20 & -1.04 & ZMB & -1.12 & -1.06 \\
\hline IS R & -1.13 & -1.06 & & & \\
\hline
\end{tabular}

${ }^{a}$ The same pattern is obtained with the median elasticities by country. 
Table 4: Trade restrictiveness indices and welfare losses

\begin{tabular}{|c|c|c|c|c|c|c|c|c|c|c|c|}
\hline Country & $\begin{array}{c}\text { Simple } \\
\text { Average } \\
\text { Tariff }\end{array}$ & $\begin{array}{c}\text { Import } \\
\text { Weighted } \\
\text { Tariff } \\
\end{array}$ & $\mathrm{TRI}^{a}$ & $\begin{array}{c}\text { Variance } \\
\text { of } \\
\text { Tariff } \\
\end{array}$ & $\begin{array}{c}\text { DWL } \\
\text { (Million } \\
\text { of US } \$ \text { ) }\end{array}$ & Country & $\begin{array}{c}\text { Simple } \\
\text { Average } \\
\text { Tariff } \\
\end{array}$ & $\begin{array}{c}\text { Import } \\
\text { Weighted } \\
\text { Tariff } \\
\end{array}$ & $\mathrm{TRI}^{\mathrm{a}}$ & $\begin{array}{c}\text { Variance } \\
\text { of } \\
\text { Tariff } \\
\end{array}$ & $\begin{array}{c}\text { DWL } \\
\text { (Million } \\
\text { of US } \$ \text { ) }\end{array}$ \\
\hline ALB & 11.96 & 11.92 & 13.56 & 44.06 & 6.3 & KOR & 8.52 & 5.41 & 8.12 & 41.87 & 273 \\
\hline A RG & 14.49 & 13.93 & 15.06 & 31.13 & 303 & L B N & 6.37 & 6.94 & 11.99 & 91.82 & 38.9 \\
\hline AUS & 4.8 & 4.88 & 7.19 & 42.43 & 95 & L K A & 7.72 & 7.77 & 14.86 & 71.02 & 23.6 \\
\hline AUT & 4.58 & 4.32 & 6.52 & 18.9 & 132 & LT U & 3.8 & 3.13 & 7.71 & 62.44 & 11.9 \\
\hline B EL & 4.6 & 4.74 & 7.17 & 19.28 & 312 & LVA & 3.32 & 2.6 & 6.48 & 45.85 & 4.52 \\
\hline BFA & 12.42 & 10.78 & 13.01 & 46.26 & 4.8 & MAR & 28.82 & 24.54 & 31.99 & 514.29 & 390 \\
\hline B GD & 20.07 & 18.82 & 23.91 & 180.55 & 106 & MDG & 4.43 & 3.93 & 5.86 & 16.65 & 0.84 \\
\hline B L R & 10.76 & 9.62 & 11.52 & 35.65 & 29.4 & MEX & 17.55 & 16.18 & 21.29 & 143.42 & 1970 \\
\hline B OL & 8.94 & 8.08 & 8.82 & 7.3 & 6.01 & MLI & 12.09 & 9.75 & 11.9 & 44.06 & 2.13 \\
\hline B R A & 14.27 & 12.18 & 14.96 & 35.51 & 527 & MUS & 18.97 & 11.43 & 24.29 & 690.61 & 49.6 \\
\hline C A F & 17.81 & 16.45 & 19.21 & 91.13 & 2.43 & M W I & 13.08 & 9.93 & 13.58 & 92.57 & 3.52 \\
\hline CAN & 4.6 & 3.71 & 6.3 & 35.91 & 187 & MYS & 8.66 & 6.81 & 17.41 & 131.45 & 671 \\
\hline CHL & 6.98 & 6.74 & 6.85 & 0.1 & 29.8 & NGA & 24.16 & 18.07 & 27.15 & 457.7 & 180 \\
\hline $\mathrm{CHN}$ & 15.94 & 16.3 & 24.38 & 135.7 & 4070 & N IC & 4.98 & 7.33 & 14.12 & 41.88 & 7.69 \\
\hline CIV & 12 & 9.82 & 11.73 & 46.92 & 14.7 & NLD & 4.59 & 4.44 & 6.86 & 19.31 & 279 \\
\hline CMR & 16.35 & 13.37 & 16.06 & 80.48 & 16.4 & NOR & 2.21 & 1.63 & 9.46 & 157.49 & 144 \\
\hline $\mathrm{COL}$ & 12.42 & 11.08 & 13.74 & 38.56 & 110 & NZL & 3.04 & 3.47 & 5.08 & 15.26 & 14.1 \\
\hline CRI & 5.52 & 4.98 & 8.38 & 50.17 & 13.2 & OMN & 7.64 & 13.28 & 28.55 & 88.13 & 83.4 \\
\hline CZE & 5.06 & 4.53 & 7.81 & 46.19 & 69.5 & PER & 13.59 & 13.27 & 13.7 & 13.05 & 67.5 \\
\hline DEU & 4.56 & 4.69 & 7.22 & 19.84 & 912 & PHL & 5.43 & 3.9 & 8.51 & 29.79 & 101 \\
\hline D NK & 4.6 & 4.4 & 6.86 & 19.29 & 81.4 & POL & 11.2 & 7.8 & 14.16 & 204.45 & 372 \\
\hline D Z A & 18.45 & 13.96 & 17.48 & 97.57 & 139 & PRT & 4.64 & 4.8 & 7.04 & 20.14 & 67.2 \\
\hline EG Y & 18.59 & 13.02 & 19.54 & 192.69 & 255 & PRY & 13.35 & 12.82 & 14.04 & 34.13 & 18.8 \\
\hline ESP & 4.58 & 4.5 & 7.1 & 19.93 & 260 & ROM & 17.14 & 15.94 & 21.84 & 137.93 & 188 \\
\hline EST & 0.07 & 0.54 & 2.37 & 0.88 & 0.9 & RWA & 9.66 & 9.28 & 11.91 & 47.49 & 1.48 \\
\hline ETH & 17.88 & 14.1 & 18.64 & 159.17 & 17.4 & S A U & 11.3 & 9.95 & 11.04 & 12.6 & 162 \\
\hline F IN & 4.61 & 4.02 & 6.58 & 19.04 & 49 & SDN & 4.98 & 5.1 & 20.1 & 125.3 & 24.5 \\
\hline F R A & 4.57 & 4.65 & 7.51 & 19.91 & 737 & SEN & 12.36 & 10.62 & 12.4 & 47.42 & 9.44 \\
\hline G A B & 18.4 & 14.87 & 17.77 & 90.55 & 13.6 & S G P & 0 & 0 & 0 & 0 & 0 \\
\hline G B R & 4.58 & 4.56 & 7 & 20.01 & 602 & SLV & 7.35 & 7.26 & 11.02 & 79.44 & 15.5 \\
\hline G H A & 12.95 & 9.91 & 13.65 & 103.3 & 16.8 & SVN & 10.22 & 10.88 & 12.98 & 39.78 & 69.7 \\
\hline G RC & 4.69 & 4.41 & 7.15 & 20.18 & 58 & SWE & 4.6 & 3.99 & 6.36 & 19.22 & 103 \\
\hline G TM & 6.69 & 6.39 & 9.57 & 62.39 & 15.5 & THA & 15.41 & 12.36 & 19.74 & 177.33 & 779 \\
\hline H K G & 0 & 0 & 0 & 0 & 0 & TTO & 8.2 & 7.66 & 12.55 & 102.01 & 14.5 \\
\hline HND & 7.12 & 7.53 & 11.04 & 50.44 & 10.7 & T UN & 28.86 & 27.47 & 30.42 & 175.13 & 302 \\
\hline HUN & 9.24 & 8.11 & 12.65 & 95.5 & 134 & TUR & 9.25 & 6.41 & 15.99 & 345.43 & 396 \\
\hline ID N & 6.76 & 5.02 & 10.02 & 99.35 & 140 & T Z A & 16.39 & 14.53 & 16.97 & 75.97 & 17.1 \\
\hline IND & 31.87 & 30.88 & 36.61 & 178.2 & 1740 & U G A & 7.95 & 7.53 & 9.46 & 32.44 & 3.63 \\
\hline IR L & 4.64 & 4.02 & 6.89 & 20.27 & 57.4 & U K R & 6.57 & 4.16 & 8.43 & 47.86 & 40.3 \\
\hline IS L & 4.15 & 3.71 & 8.03 & 51.86 & 5.35 & URY & 14.64 & 14.22 & 15.37 & 36.74 & 37 \\
\hline ITA & 4.58 & 4.59 & 7.31 & 19.93 & 517 & USA & 4.17 & 3.93 & 15.18 & 134.81 & 7070 \\
\hline JOR & 15.58 & 13.26 & 18.88 & 192.14 & 51.1 & VEN & 12.69 & 13.74 & 15.84 & 37.22 & 156 \\
\hline JP N & 3.29 & 3.05 & 6.17 & 22.99 & 512 & $\mathrm{ZAF}$ & 8.02 & 6 & 11.92 & 127.64 & 146 \\
\hline KEN & 17.96 & 17.07 & 23.05 & 176.69 & 49.9 & ZMB & 11.71 & 10.08 & 13.28 & 87.5 & 4.44 \\
\hline
\end{tabular}

${ }^{a}$ This is Feenstra's (1995) linear approximation of Anderson and Neary's $(1992,1994)$ trade restrictiveness index. 
Figure 1: Distribution of the estimated import demand elasticities at HS six digit level

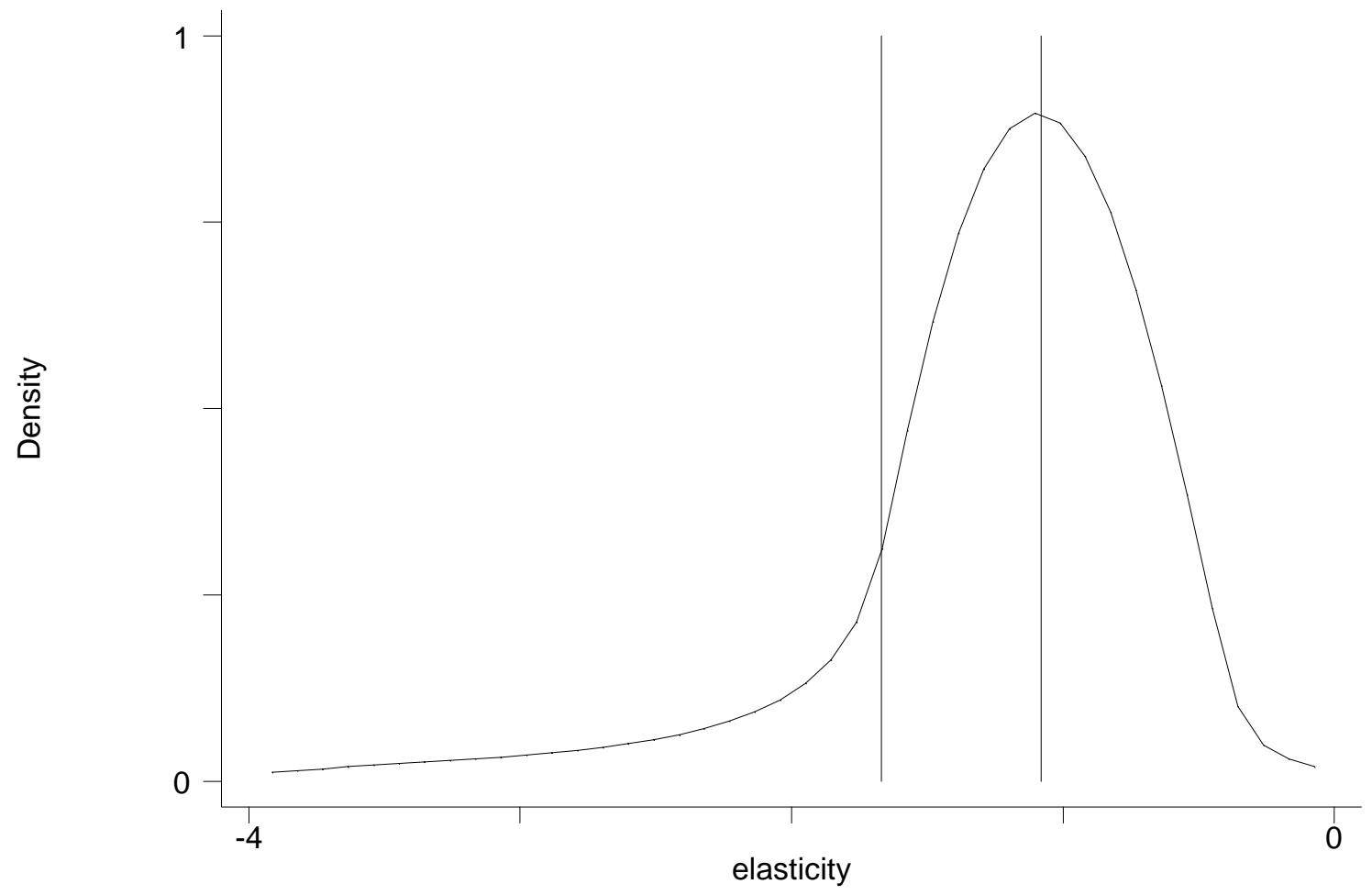


Figure 2: Distribution of import demand elasticities: Metal vs. Machinery

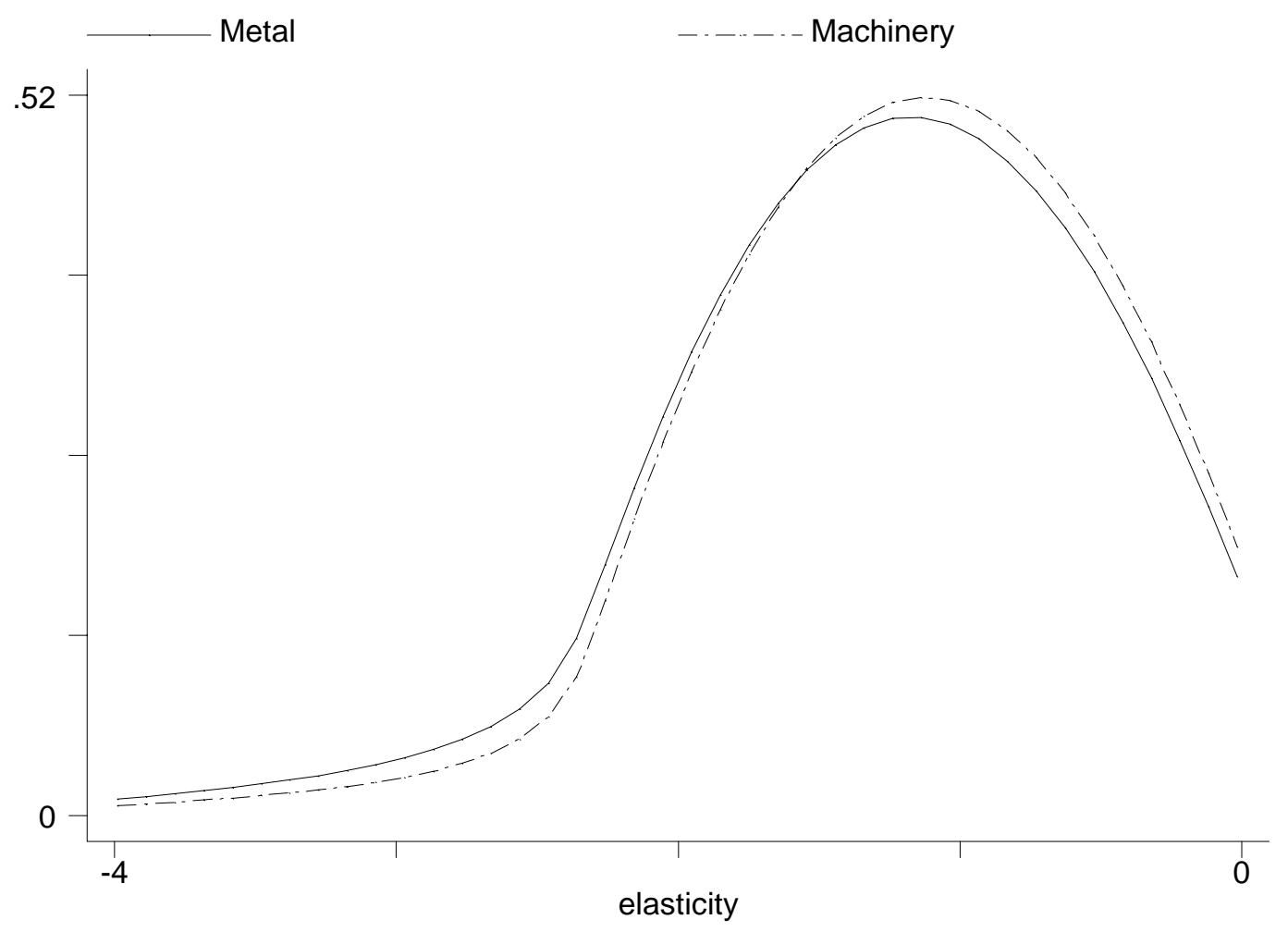


Figure 3: Import demand elasticities and Log of GDP

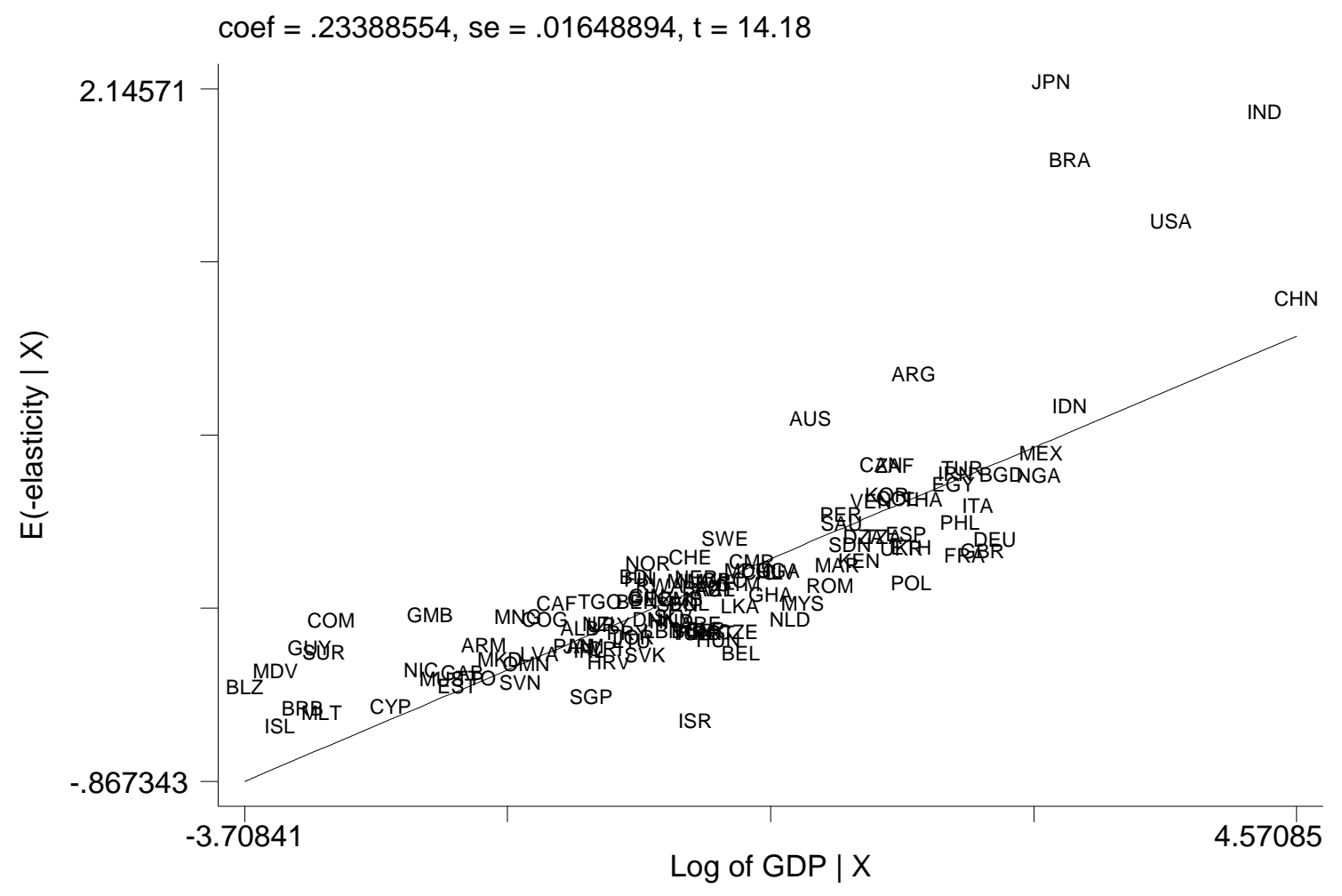


Figure 4: Import demand elasticities and Log of GDP per capita

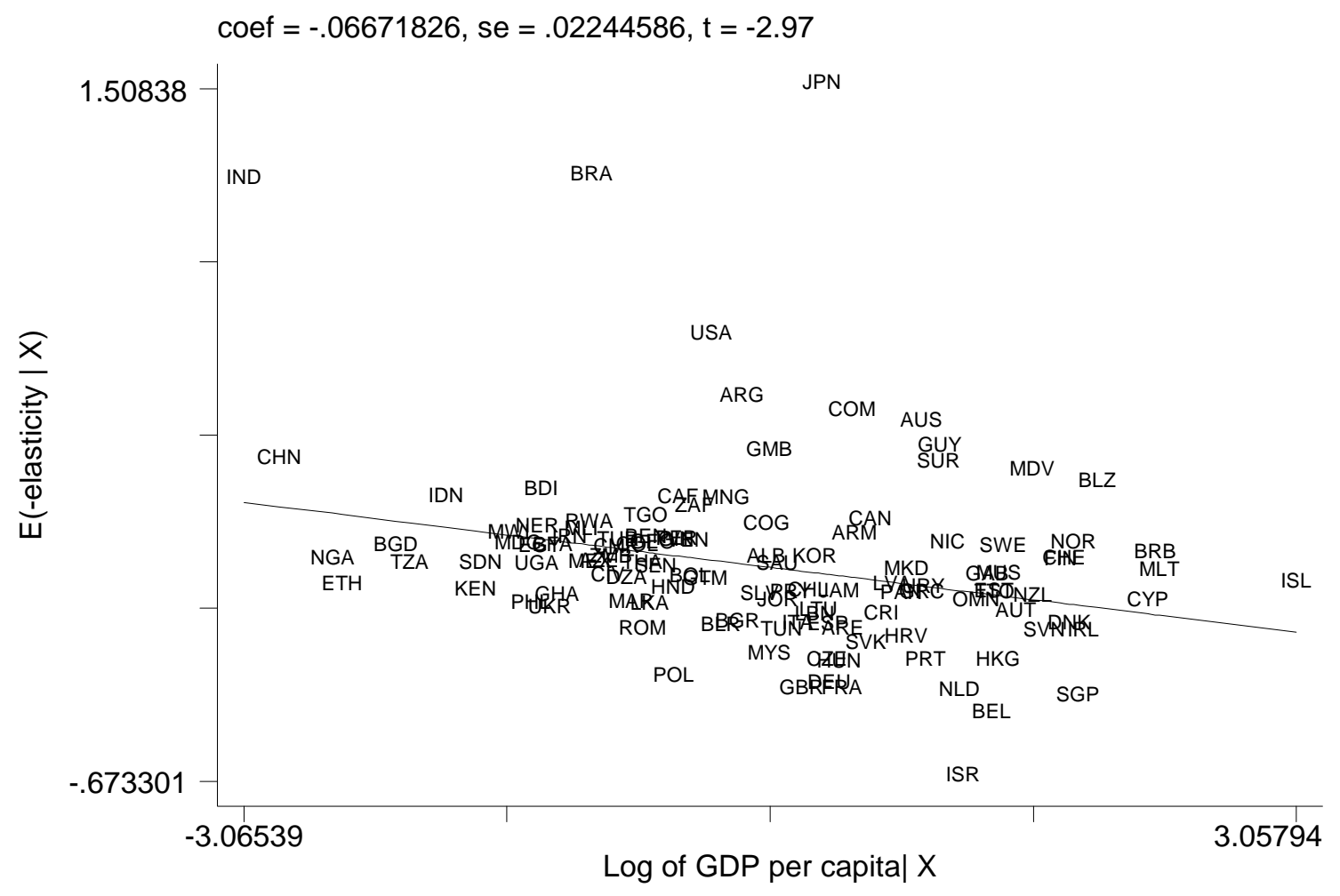


Figure 5: TRI versus Simple Average Tariffs by Country

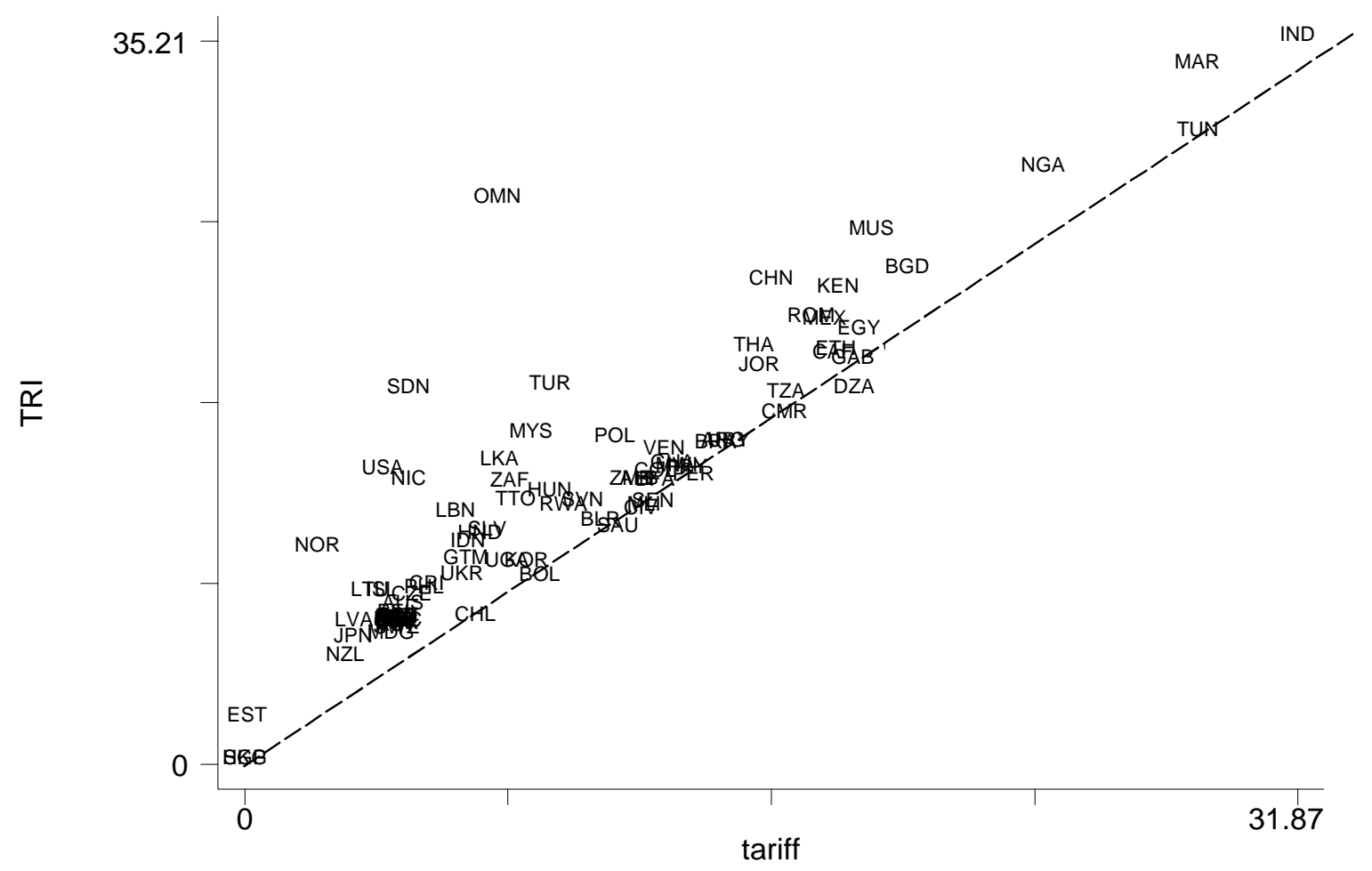

